\title{
Reforma energética, ¿era realmente necesaria?
}

\author{
Energy Reform ¿was it really needed?
}

\author{
José Luis Clavellina Miller* :
}

\section{Resumen}

Constitucionalmente, el sector energético mexicano fue reformado en diciembre de 2013. Dicha reforma tuvo por objeto ampliar el papel que el sector privado juega en la producción de hidrocarburos y electricidad del país. Los principales argumentos del Gobierno Federal a favor de los cambios Constitucionales propuestos eran la falta de recursos para invertir, los altos riesgos inherentes a las actividades de exploración y producción, así como la dificultad técnica y financiera para explotar el petróleo en aguas profundas. El presente trabajo tiene por objeto analizar la situación financiera de Petróleos Mexicanos (Pemex), así como su carga fiscal; se compran además, los resultados operativos de la paraestatal con otras compañías petroleras en el mundo, a fin de determinar si la reforma energética aprobada era realmente la que se necesitaba. Se describe la Iniciativa de reforma energética presentada por el Ejecutivo Federal, la del Partido Acción Nacional (PAN) y la del Partido de la Revolución Democrática (PRD), así como lo que finalmente fue aprobado por el Congreso de la Unión. Se concluye que lo que verdaderamente requería Pemex era una reforma fiscal que le permitiera financiar su gasto de inversión, pues su rentabilidad operativa era de las más altas a nivel mundial.

Palabras clave:

- Energía y macroeconomía

- Política Gubernamental

- Hidrocarburos

\begin{abstract}
Some articles of the Mexican Constitution related to the energy sector regulation were changed in December, 2013. The aim of those changes was to enhance the private sector role in oil and electricity production. The main Federal Government arguments to support the Constitutional modifications was the lack of internal financial resources to invest, high inherent risks in the exploration and production activities, and the lack of technology to explore deep water oilfields. This essay pretends to analyze the financial and fiscal situation of Pemex. It also compares some of the most relevant financial results with other oil companies around the world, in order to determine if the energy related changes, approved by the Congress, were really needed. The amendment proposed by the President as well as those presented by the PAN and PRD parties, are also described. The conclusion is that what Pemex really needed was a fiscal reform which allowed it to finance its own investment decisions, due to the fact that its profitability (before taxes) is one of the highest among the studied oil companies.
\end{abstract}

\section{Keywords:}

- Energy and Macroeconomy

- Goverment Policy

- Hydrocarbon

JEL: Q43, Q48

\footnotetext{
* Doctor en Economía por la UnAM. Actualmente es profesor en la División de Estudios Profesionales y en la División de Estudios de Posgrado de la Facultad de Economía de la UnAM e investigador en la Dirección de Estudios Macroeconómicos y Sectoriales del Centro de Estudios de las Finanzas Públicas de la Cámara de Diputados. . . .
} 
Economía Informa núm. 385 marzo - abril • 2014 - "

\section{Introducción}

Desde su creación Pemex se convirtió en símbolo de soberanía para México. A lo largo de su historia ha jugado un papel importante en la actividad económica del país, al ser un pilar de las finanzas públicas y aportar cerca de $34 \%$ de los ingresos de la federación y abastecer de productos petrolíferos a la industria mexicana. Además, a partir de la expropiación (1938), la paraestatal se constituyó en un ente fundamental para el desarrollo económico e industrial del país, al convertirse en un enlace entre diversos sectores productivos a los que abastece de energéticos y materias primas. Así, la importancia de Pemex como empresa pública es inobjetable además, por el peso que tiene como fuente generadora de divisas y como agente para el desarrollo (García B., 2000).

No obstante, el hecho de que Pemex apuntale al presupuesto de la federación, ha coartado la posibilidad de que disponga de los excedentes financieros necesarios para reponer sus activos e introducir las innovaciones tecnológicas necesarias para asegurar el abastecimiento interno de productos petrolíferos. Por lo anterior, promover cambios en su estructura organizacional y fiscal resulta esencial para permitirle alcanzar una mayor competitividad y seguir apoyando la industrialización y el crecimiento económico del país.

Hoy en día, las condiciones de competencia internacional que permean la actividad económica, hacen necesario que todas las empresas (incluso las públicas) se vean obligadas a elevar su eficiencia y productividad. En ese sentido, en 2013 los principales partidos políticos representados en el Congreso de la Unión presentaron distintas iniciativas de reforma energética. Algunas de ellas buscaron ampliar la participación del sector privado en materia petrolera, procurando mantener la rectoría del estado en el sector; en tanto que otras, pretendían modernizar y hacer más transparente la operación de Pemex, dotándola de mayor autonomía de gestión.

\section{Pemex en el Contexto Internacional}

Pemex tiene la encomienda de "maximizar el valor de los activos petroleros y los hidrocarburos de la nación, satisfaciendo la demanda nacional de productos petrolíferos con la calidad requerida, de manera segura, confiable, rentable y sustentable."1 En 2012, El total de reservas de hidrocarburos era de 43837.3 millones de barriles de petróleo crudo, de las cuales 40\% eran reser-

1 www.pemex.com, 
vas posibles, $28 \%$ reservas probables y $31 \%$ reservas probadas. A enero de 2013 , las reservas probadas de petróleo crudo con que contaba el país ascendieron a 10703 millones de barriles, lo que ubicó a México en el lugar 18 a nivel mundial. Mientras, en lo que se refiere a las reservas probadas de gas natural, nuestro país contaba con 17 billones de pies cúbicos, colocándolo en la posición 30.

\section{Cuadro I}

Reservas Probadas de Petróleo Crudo, Principales Países, 2013

(millones de barriles)

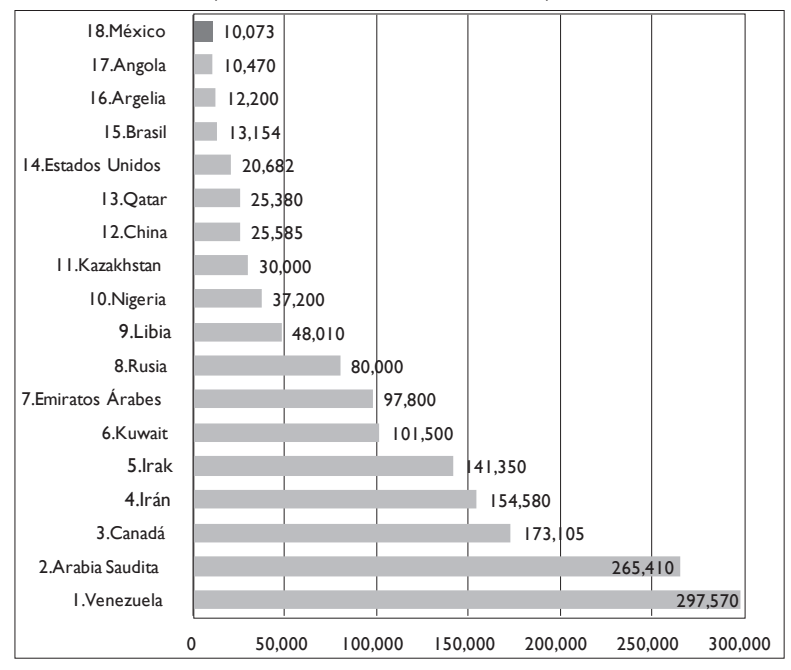

\section{Reservas Probadas de Gas natural}

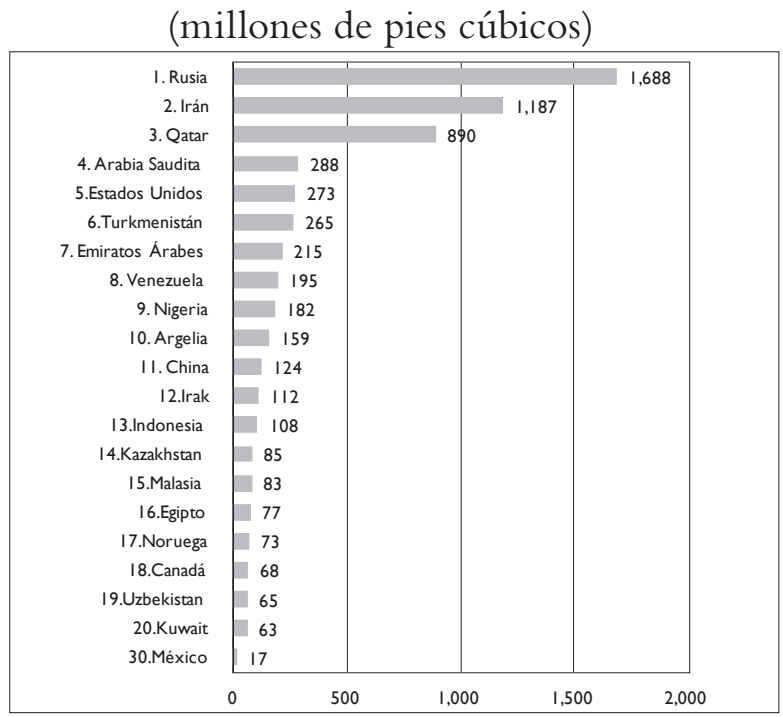

Fuente: Pemex. 
Economía Informa núm. 385 marzo - abril • 2014 - "

En 2012, la capacidad de producción de petróleo crudo de Pemex fue de 2548.1 miles de barriles diarios, lo que lo ubicó como el décimo productor de petróleo a nivel mundial. Además, Petróleos Mexicanos cuenta con seis refinerías, con un capacidad de 1690 miles de barriles diarios, esto es, de 66\% del petróleo crudo que se produce en el país. Esta capacidad de destilación primaria ubicó al país en la posición 13 en el ámbito internacional.

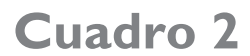

Producción de Petróleo Crudo 2012

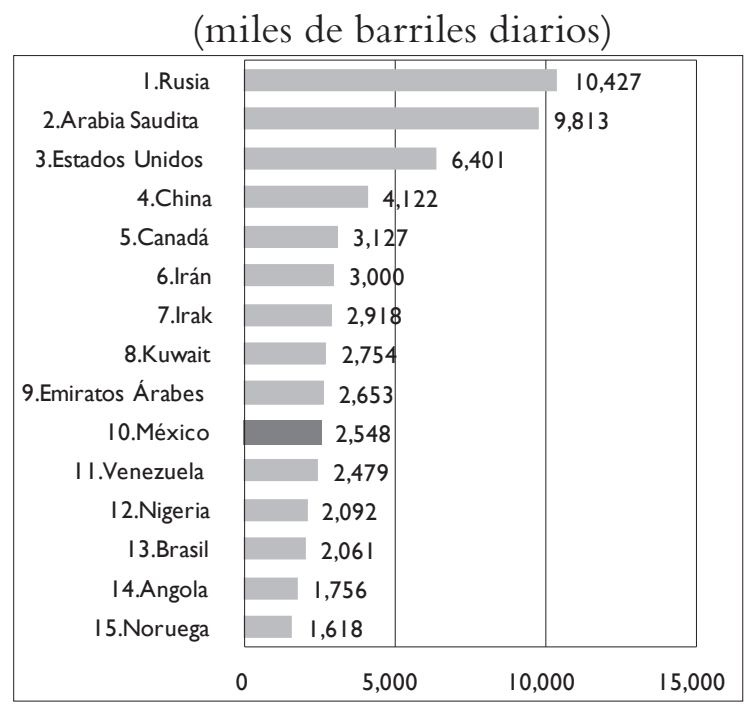

Fuente: Pemex.

\begin{tabular}{|l|l|l|}
\hline \multicolumn{2}{c|}{ Capacidad de Destilación Primaria 2011 } \\
\hline \multicolumn{1}{|c|}{ Empresa } & \multicolumn{1}{c|}{ País } & Miles de barriles diarios \\
\hline 1.Exxon Mobil & Estados Unidos & 6218 \\
2.Sinopec & China & 5563 \\
3.CNPC & China & 3607 \\
4.Royal Dutch Shell & Reino Unido / Holanda & 3251 \\
5.PDVsa & Venezuela & 2822 \\
6.ConocoPhillips & Estados Unidos & 2365 \\
7.BP & Reino Unido & 2352 \\
8.Saudi Aramco & Arabia Saudita & 2214 \\
9.Total & Francia & 2088 \\
10.Petrobras & Brasil & 2013
\end{tabular}




\begin{tabular}{|l|l|l|}
\hline 11.Chevron & Estados Unidos & 1967 \\
\hline 12.NIOC & Irán & 1772 \\
\hline 13.Petróleos Mexicanos & México & 1690 \\
\hline 14.KPC & Kuwait & 1136 \\
\hline 15.Gasprom & Rusia & 1135 \\
\hline
\end{tabular}

Fuente: Pemex.

En 2011 Pemex fue la empresa número 11 a nivel mundial, con ventas por 125.3 mil millones de dólares. Sus dos principales competidores latinoamericanos, Petrobras y PDVsA, se encontraron en los lugares 10 y 12 , respectivamente, con ventas que alcanzaron los 145.9 y 124.7 mil millones de dólares, en cada caso.

\section{Cuadro 3}

\section{Ventas Totales 2011}

(millones de dólares)

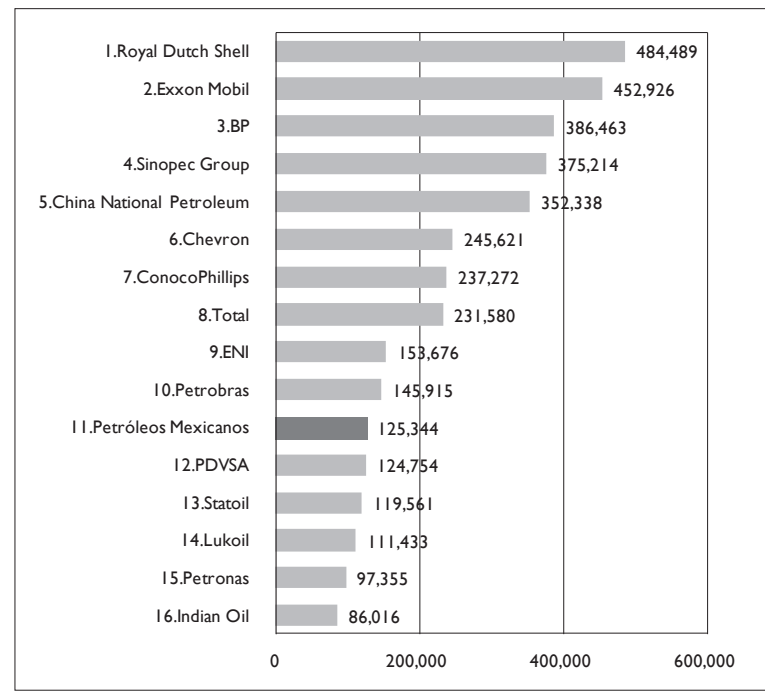

Fuente: Pemex.

La relevancia que ha adquirido Pemex en la producción de petrolíferos a nivel internacional enfrenta riesgos importantes. De 2000 a 2012, la tasa de crecimiento media anual para la producción de petróleo crudo fue de $-2.18 \%$, en tanto que para los condensados y líquidos del gas fue de $-1.11 \%$. Asimismo, el procesamiento de crudo y la producción de petrolíferos y naftas presentaron 
Economía Informa núm. 385 marzo - abril • 2014 - "

tasas negativas a lo largo del período. Los únicos rubros que reportaron aumentos promedio fueron el gas natural con $3.74 \%$, y la producción de petroquími$\cos \operatorname{con} 0.78 \%$.

Cuadro 4

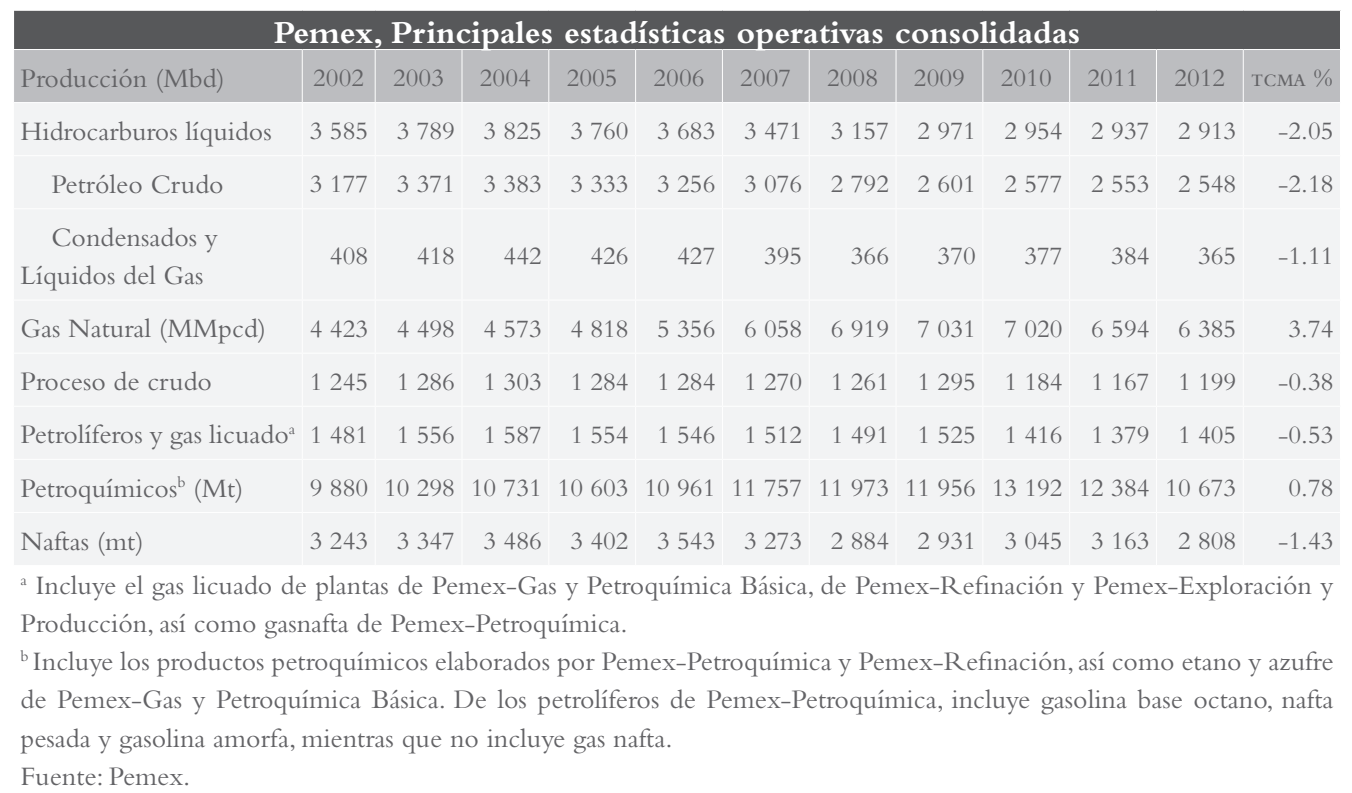

En cuanto al comercio exterior, de 2000 a 2012 las exportaciones petroleras crecieron a una tasa promedio anual de $10.4 \%$, en tanto que las importaciones lo hicieron en $14.6 \%$. Lo anterior permite observar que el superávit de la balanza de productos petroleros es cada vez menor y da cuenta de la necesidad de elevar la producción de petróleo y sus derivados para asegurar el abasto interno. 


\section{Cuadro 5}

Exportaciones e Importaciones Petroleras, 1993-2012

(millones de dólares)

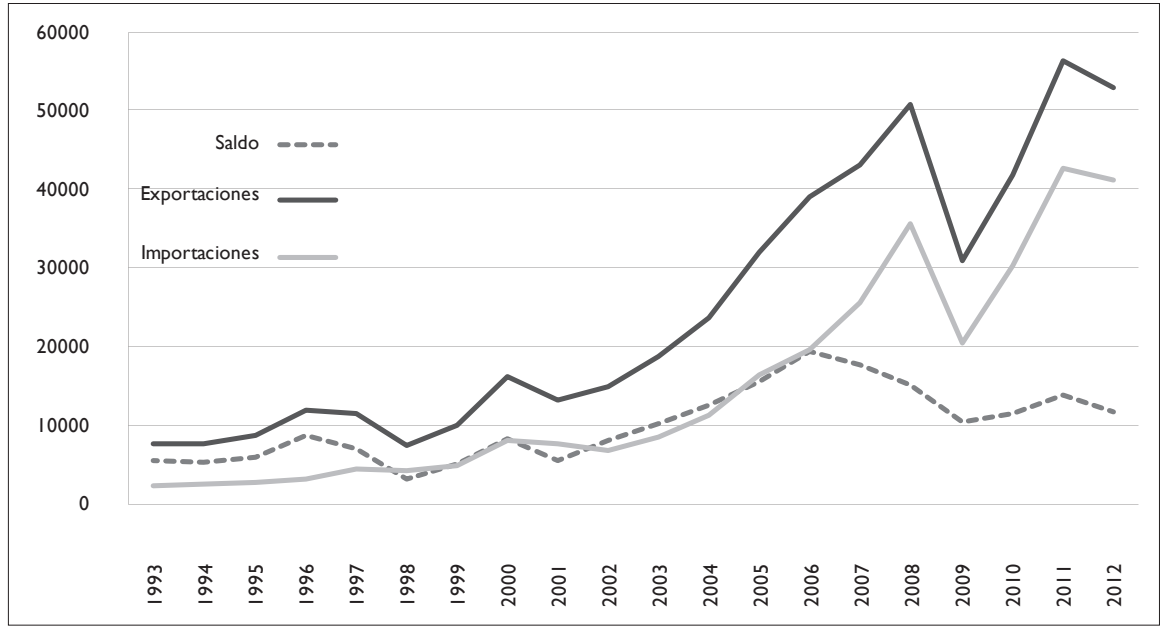

Fuente: elaborado por el CEFP con datos de Banxico.

En cuanto a la inversión en Pemex, en 2012 ésta fue de 311,993 millones de pesos, ${ }^{2}$ lo cual representó 2\% del piB. En el periodo de estudio (2002-2012), la inversión en la Paraestatal creció a una tasa promedio anual de 11\%. Llama la atención que pese a los volúmenes crecientes de inversión, la producción observada durante los últimos años mantenga una tendencia a la baja.

\section{Cuadro 6}

\section{Pemex, Inversión en Capital}

(millones de pesos)

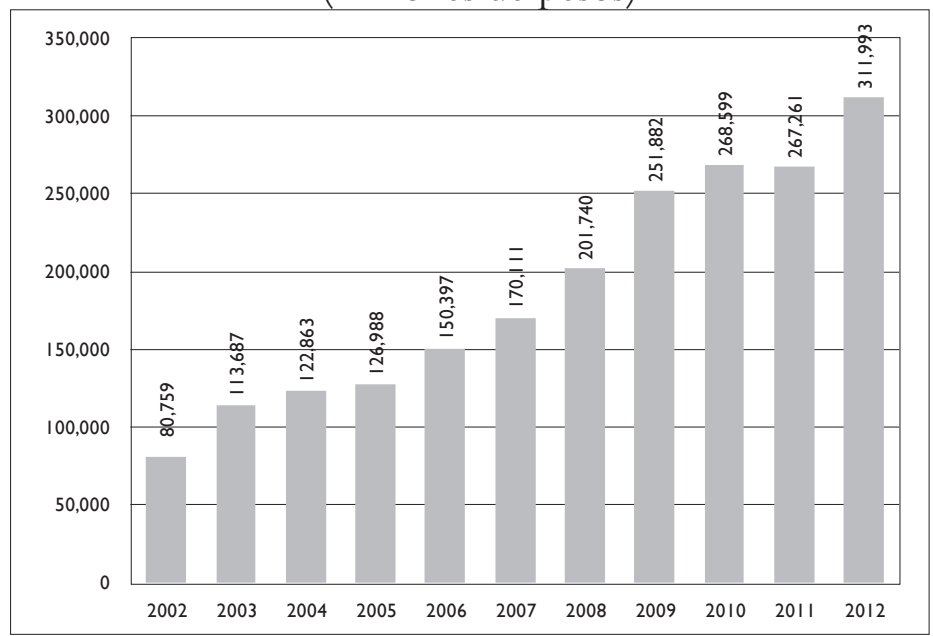

Fuente: Pemex.

\footnotetext{
2 Pemex, Anuario Estadístico 2012.
} 


\section{Régimen Fiscal de Pemex}

Pemex es el mayor contribuyente del fisco nacional, de 2000 a 2012, en promedio, aportó $34 \%$ de los ingresos totales del sector público. El régimen fiscal de la paraestatal ha tenido varios cambios durante los últimos años.

\section{Cuadro 7}

\section{Ingresos Petroleros del Sector Público Presupuestario}

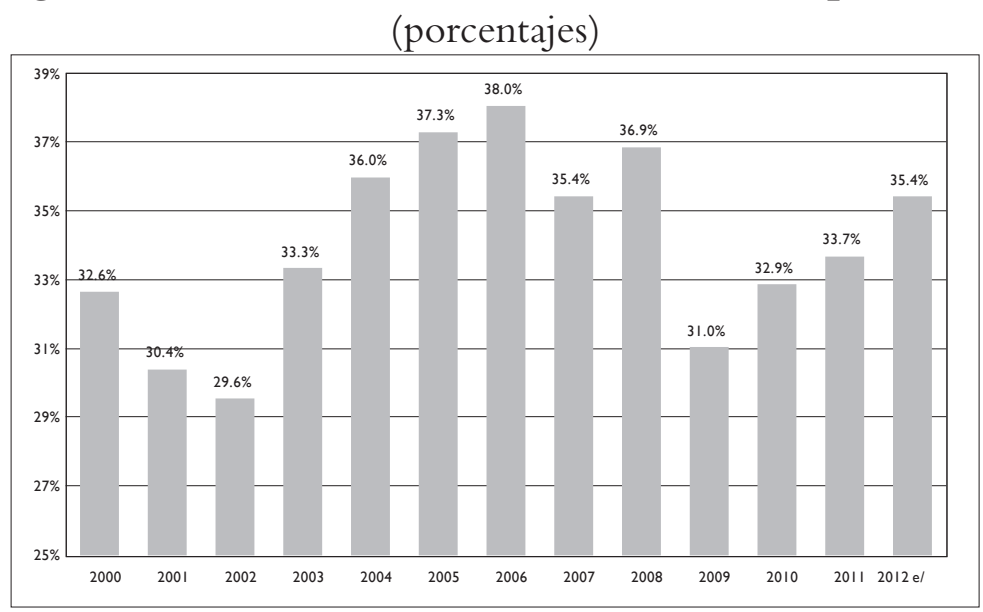

Fuente: CEFP.

En noviembre de 2005, el Congreso de la Unión aprobó cambios en la tributación de Pemex, pues el pago de los derechos se realizó con base al valor de la producción de petróleo crudo y gas natural y no en el valor de sus ventas como previamente se hacía. Anteriormente Pemex, pagaba tres derechos y bajo este régimen se adicionaron los que gravaron tanto la extracción de petróleo crudo y gas así como su exportación.

\section{Cuadro 8}

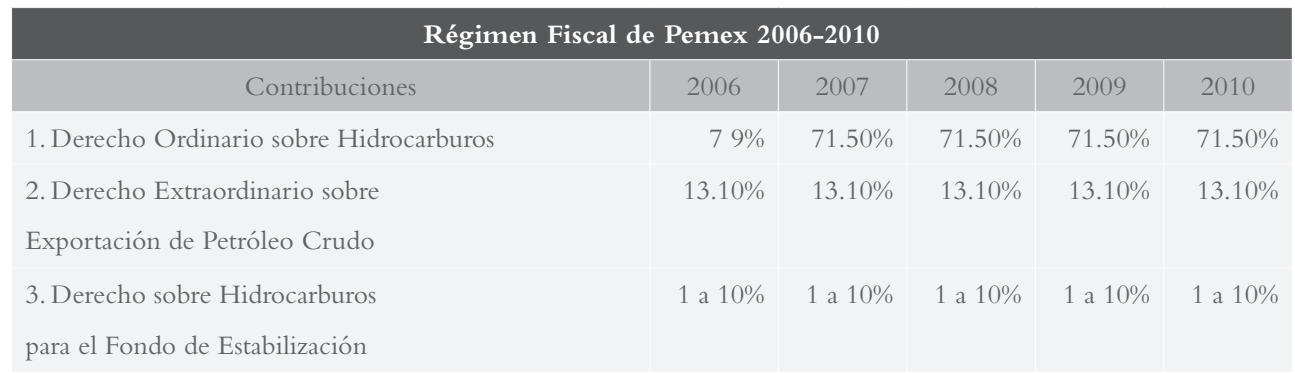




\begin{tabular}{|c|c|c|c|c|c|}
\hline $\begin{array}{l}\text { 4. Derecho para el Fondo de Investigación Científica } \\
\text { y Tecnológica en Materia de Energía }\end{array}$ & $5.00 \%$ & $0.65 \%$ & $0.65 \%$ & $0.65 \%$ & $0.65 \%$ \\
\hline 5. Derecho para Fiscalización Petrolera & $0.00 \%$ & $0.00 \%$ & $0.00 \%$ & $0.00 \%$ & $0.00 \%$ \\
\hline 6. Derecho Único sobre Hidrocarburos: & 37 a $57 \%$ & 37 a $57 \%$ & 37 a $57 \%$ & & \\
\hline $\begin{array}{l}\text { 7. Derecho sobre la Extracción de Hidrocarburos Pa- } \\
\text { leocanal de Chicontepec y Campos de Aguas Profundas }\end{array}$ & & & 10 a $20 \%$ & $15.00 \%$ & $15.00 \%$ \\
\hline $\begin{array}{l}\text { 8. Derecho Especial sobre Hidrocarburos Paleocanal de } \\
\text { Chicontepec }\end{array}$ & & & $71.50 \%$ & 30 a $36 \%$ & 30 a $36 \%$ \\
\hline $\begin{array}{l}\text { 9. Derecho Especial sobre Hidrocarburos Campos de } \\
\text { Aguas Profundas }\end{array}$ & & & $\begin{array}{r}60 \mathrm{a} \\
71.5 \%\end{array}$ & & \\
\hline $\begin{array}{l}\text { 10. Derecho Adicional sobre Hidrocarburos Paleocanal } \\
\text { de Chicontepec y Campos de Aguas Profundas: }\end{array}$ & & & & $52.00 \%$ & $52.00 \%$ \\
\hline 11. Impuesto a los Rendimientos Petroleros & $30.00 \%$ & $30.00 \%$ & $30.00 \%$ & $30.00 \%$ & $30.00 \%$ \\
\hline 12. Aprovechamiento sobre Excedentes Petroleros & $6.50 \%$ & & & & \\
\hline
\end{tabular}

Fuente: Huerta et al., 2012.

Para 2006 (un año después de la entrada en vigor del nuevo régimen), la empresa enteró a la Federación por concepto de impuestos, derechos y aprovechamientos 582,855 millones de pesos y obtuvo una ganancia neta de 45,252 millones de pesos.

A finales de 2008 se adicionaron tres derechos que distinguían a las zonas de difícil acceso y altos costos de explotación, gravándolas de forma diferente, de acuerdo con las siguientes definiciones:

Los campos en aguas profundas. ${ }^{3}$

Los campos en el Paleocanal de Chicontepec. ${ }^{4}$

Además, conviene recordar que a finales de 2008, el Congreso de la Unión aprobó una serie de iniciativas encaminadas a brindar más autonomía de gestión a la paraestatal, a sanear sus finanzas e impulsar inversiones. Dichas re-

\footnotetext{
3 Se refiere a aquellos campos de extracción de petróleo crudo y gas natural que, en promedio, sus pozos se encuentren ubicados en zonas con un tirante de agua superior a 500 metros.

4 Son aquellos campos de extracción de petróleo crudo y gas natural ubicados en los municipios de Castillo de Teayo, Coatzintla, Coyutla, Chicontepec, Espinal, Ixhuatlán de Madero, Temapache, Papantla, Poza Rica de Hidalgo, Tepetzintla o Tihuatlán, en el Estado de Veracruz de Ignacio de la Llave, o en los municipios de Francisco Z. Mena, Pantepec o Venustiano Carranza, en el Estado de Puebla.
} 
Economía Informa núm. 385 marzo - abril • 2014 - "

formas incluyeron la modificación de la Ley Reglamentaria del artículo 27 constitucional en el ramo del petróleo en las que se establecía que Pemex podría celebrar con personas físicas o morales los contratos de obras y de prestación de servicios. Las remuneraciones que en dichos contratos se establezcan serían siempre en efectivo y en ningún caso se concedería la propiedad sobre los hidrocarburos, ni se podrán suscribir contratos de producción compartida o alguno que comprometiera a porcentajes de la producción o del valor de las ventas, ni de las utilidades. ${ }^{5}$

Por otro lado, las modificaciones aprobadas a la Ley Orgánica de Pemex, dieron a la paraestatal autonomía en materia de deuda y para emitir bonos ciudadanos; y se otorgó al Consejo de Administración la facultad de proponer al Ejecutivo Federal, la creación de organismos subsidiarios, así como aprobar adecuaciones a su presupuesto sin autorización de la Secretaría de Hacienda y Crédito Público (SHCP) (siempre que cumpla con su meta de balance financiero) ${ }^{6}$

Al cierre de 2009, la empresa pagó a la Federación por concepto de impuestos, derechos y aprovechamientos 546633 millones de pesos, por lo que reportó una pérdida de 94662 millones de pesos.

En noviembre de 2010, se publicaron en el Diario Oficial de la Federación, reformas a la Ley Federal de Derechos que homologaron el pago de derechos correspondiente a los campos del Paleocanal de Chicontepec y de aguas profundas (bajo el argumento de que el costo y dificultad para acceder a dichas

5 Otras modificaciones a la Ley reglamentaria del artículo 27 constitucional en el ramo del petróleo fueron las siguientes:

- Los yacimientos transfronterizos podrán ser explotados en los términos de los tratados en los que México sea parte, celebrados por el Presidente de la República y aprobados por la Cámara de Senadores.

- Pemex deberá incorporar en la Estrategia Nacional de Energía la orientación de su participación en el mercado mundial, de acuerdo con los intereses nacionales (seguridad energética, sustentabilidad de la plataforma anual de extracción, diversificación de mercados, incorporación del mayor valor agregado a sus productos, desarrollo de la planta productiva nacional y protección del medio ambiente) (CEFP, 2008).

${ }^{6}$ Las reformas de este año también incluyeron a la Ley de la Comisión Reguladora de Energía, a través de la creación de la Comisión Reguladora del Petróleo, que en conjunto con la Comisión del Petróleo, supervisa la aplicación de la normatividad técnica y otorga los permisos para la ejecución de los trabajos petroleros. Se dictó la Ley para el Aprovechamiento de Energías Renovables y el Financiamiento de la Transición Energética. Se reformó el artículo 33 de la Ley Orgánica de la administración Pública Federal, otorgándole nuevas facultades a la Secretaría de Energía, entre las que destacan: Conducir la política energética de México, así como vigilar las políticas en materia de energía; atender en todo momento los principios de soberanía, seguridad energética y restitución de hidrocarburos y Promover energías alternas a los hidrocarburos y se promulgó la Ley para el Aprovechamiento Sustentable de la Energía. De igual manera se previó la creación del Subsistema Nacional de Información sobre el Aprovechamiento de la Energía (CEFP, 2008). 
reservas son similares entre sí), por lo que se eliminaron los tres derechos que fueron agregados en 2008, y se adicionaron los siguientes:

- Derecho sobre Extracción de Hidrocarburos (DSEH): En el régimen anterior, la tasa era de 10 a 20\% según el precio sobre el valor del petróleo crudo y gas natural extraído, en el nuevo régimen, la tasa era de 15\% sobre la misma base.

- Derecho Especial sobre Hidrocarburos (DEH): Con este derecho se homologaron las tasas anteriores de derecho sobre hidrocarburos en aguas profundas y para Paleocanal de Chicontepec, (CEFP, 2009).

- Derecho adicional sobre Hidrocarburos (DAH): Este impuesto anual sobre hidrocarburos se pagaba cuando el valor promedio acumulado extraído en el campo del que se trate, fuera mayor a 60 dólares, y se calculaba aplicando una tasa de $52 \%$, a esa diferencia multiplicada por el volumen de petróleo crudo equivalente extraído en el campo de que se trate en el año (Pemex, memoria de labores, 2011).

Al final del ejercicio 2011, la empresa pagó a la Federación por concepto de impuestos, derechos y aprovechamientos 876016 millones de pesos y reportó una pérdida de 106942 millones de pesos.

\section{Cuadro 9}

\section{Pemex, Rendimiento Neto}

(millones de pesos)

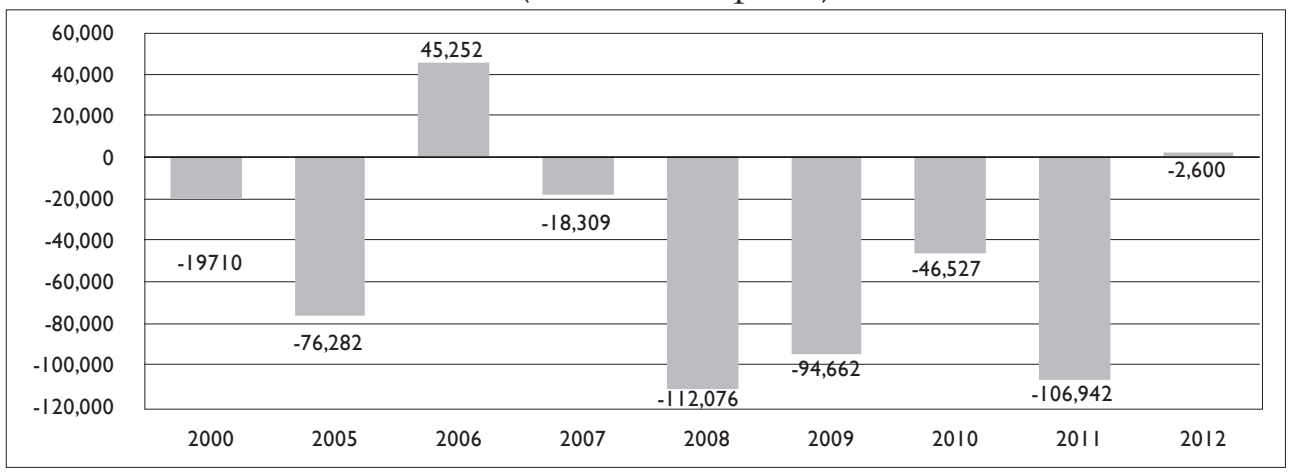

Fuente: Pemex.

Bajo el régimen fiscal de 2012, Pemex pagó los siguientes derechos, impuestos y contribuciones: ${ }^{7}$

7 Pemex, estados financieros consolidados 2012. 
Economía Informa núm. 385 marzo - abril • 2014 ㅁ =

(a)Derecho ordinario sobre hidrocarburos (DOSH)- La tasa aplicable en 2012 fue de $71.5 \%$ y de $72.5 \%$ en $2011 .{ }^{8}$

(b) Derecho sobre hidrocarburos para el fondo de estabilización- PEP es el obligado al pago anual de este derecho, cuando en el año el precio promedio ponderado del barril de petróleo crudo exportado excediera los US $\$ 22 .{ }^{9}$

(c) Derecho extraordinario sobre la exportación de petróleo crudo- Este se calcula aplicando la tasa de $13.1 \%$ sobre el valor que resulte de multiplicar la diferencia que exista entre el precio promedio ponderado anual del barril de petróleo crudo mexicano y el precio considerado en la estimación de los ingresos de la Federación del ejercicio (US\$85 en 2012 y US\$65 en 2011), por el volumen total de exportación. ${ }^{10}$

(d) Derecho para la investigación científica y tecnológica en materia de energía- La tasa aplicable fue de $0.65 \%$ para 2012 sobre el valor anual del petróleo crudo y gas natural extraídos en el año.

(e) Derecho para la fiscalización petrolera- La tasa aplicable para 2012 fue del $0.003 \%$ sobre el valor anual del petróleo crudo y gas natural extraídos en el año.

(f) Derecho sobre extracción de hidrocarburos- Para 2012 este derecho aplicó una tasa fija de $15 \%$ al valor anual del petróleo crudo y gas natural extraído de cada uno de los campos señalados en la LFD. ${ }^{11}$

(g) Derecho especial sobre hidrocarburos- En 2012 este derecho aplicó una tasa de $30 \%$ a la diferencia entre el valor anual del petróleo crudo y gas natural extraídos en el campo de que se trate y las deducciones permitidas por la LFD. (h) Derecho adicional sobre hidrocarburos- Para 2012 Pemex Exploración y Producción está obligado al pago anual cuando el valor promedio acumulado anual del petróleo crudo equivalente por barril extraído en el campo de que se trate sea mayor a US $\$ 60 .{ }^{12}$

\footnotetext{
${ }^{8}$ La base para el cálculo de este derecho es el valor anual del petróleo crudo y gas natural extraídos en el año menos las deducciones permitidas en la LFD.

${ }^{9}$ La tasa aplicable es de 1 a $10 \%$, dependiendo del precio promedio, cuyo tope es de US\$31 a partir del cual se paga la tasa de 10\%. La recaudación anual que genere la aplicación de este derecho se destina al fondo de estabilización de los ingresos petroleros.

10 Este derecho es acreditable contra el derecho sobre hidrocarburos para el fondo de estabilización. Los ingresos provenientes de este derecho se destinan a las Entidades Federativas a través del Fondo de Estabilización de los Ingresos de las Entidades Federativas.

11 Se refiere a los siguientes:

I. Como una sola unidad, la totalidad de los campos en el Paleocanal de Chicontepec.

II. Los campos en el Paleocanal de Chicontepec que hayan sido segregados en los términos de Ley. III. Los campos en aguas profundas (Durante 2012 no hubo extracción de crudo y gas natural de campos en aguas profundas).

IV. Los campos marginales, únicamente respecto de la producción incremental anual que se obtenga una vez alcanzada la producción base anual.

12 Este último monto se actualiza cada ejercicio con el índice de precios al productor de Estados Unidos.
} 
(i) Derecho para regular y supervisar la exploración y explotación de hidrocarburos- La tasa aplicable para 2012 fue de $0.03 \%$ sobre el valor anual del petróleo crudo y gas natural extraídos en el año. ${ }^{13}$

(j) Impuesto Especial sobre Producción y Servicios (IEPS)- El IEPS se causa al momento de efectuar la enajenación e importación de gasolinas y diesel. Las tasas aplicables a este impuesto dependen de factores tales como el tipo de producto, precio de referencia, la región en la que se vende, fletes incrementables y comisiones que apliquen.

(k) Impuesto a los Rendimientos Petroleros (IRP)- El IRP, aplicable a los Organismos, excepto PEP, se calcula aplicando la tasa de 30\% sobre el excedente de la totalidad de ingresos menos las deducciones autorizadas por las reglas específicas que emite SHCP.

(l) Impuesto al valor agregado (IVA)- Para el IVA se determinan pagos mensuales definitivos en flujo, de acuerdo con las disposiciones de la Ley del IVA, aplicable a los contribuyentes de este impuesto.

(m) Impuesto Sobre la Renta- Algunas compañías subsidiarias son sujetas de la Ley del Impuesto sobre la Renta (ISR) y de la Ley del Impuesto Empresarial a Tasa Única (IETU) y se causa el que resulte mayor entre el ISR y el IETU.

Adicionalmente, Pemex está obligado al pago de Contribuciones causadas por la importación de mercancías y Contribuciones locales. Al final del ejercicio 2012, la empresa pagó a la Federación por concepto de Impuestos, Derechos y Aprovechamientos 902,646 millones de pesos y reportó un rendimiento de 2,600 millones de pesos.

\section{Situación Financiera de Pemex}

\section{Balance General}

En el balance general de Pemex se observa que la evolución del activo de la empresa, de 2000 a 2012, ha mostrado un crecimiento promedio anual de 11.2\%; en tanto que el pasivo lo hizo a una tasa de $14.1 \%$. Lo anterior, ha ocasionado una reducción de su patrimonio a una tasa de $20.8 \%$ anual.

\footnotetext{
3 El valor de estos productos se calculará de acuerdo con lo establecido para el régimen general Dosh. La recaudación se destinará a cubrir el presupuesto de la Comisión Nacional de Hidrocarburos.
} 
Economía Informa núm. 385 marzo - abril • 2014 - " " "

\section{Cuadro 10}

\begin{tabular}{|c|c|c|c|c|c|c|c|c|c|}
\hline \multicolumn{10}{|c|}{ Pemex, Balance General (Millones de pesos) } \\
\hline & 2005 & 2006 & 2007 & 2008 & 2009 & 2010 & 2011 & 2012 & TCMA $\%$ \\
\hline Activos & 1042560 & 1204734 & 1330281 & 1236837 & 1332037 & 1395197 & 1981374 & 2024183 & 11.2 \\
\hline Circulante & 292763 & 384924 & 428561 & 364292 & 349697 & 315911 & 330520 & 318142 & 9.3 \\
\hline $\begin{array}{l}\text { Propiedades, } \\
\text { mobiliario y } \\
\text { equipo }\end{array}$ & 643236 & 710488 & 793846 & 845062 & 967592 & 1061388 & 1592425 & 1658734 & 12.9 \\
\hline Otros & 106561 & 109322 & 107874 & 27483 & 14749 & 17898 & 58429 & 47307 & -2.7 \\
\hline Pasivos & 1069430 & 1164781 & 1280373 & 1209952 & 1398877 & 1506499 & 1878197 & 2295249 & 15.4 \\
\hline De corto plazo & 164476 & 169927 & 289464 & 175965 & 242960 & 207254 & 253445 & 235804 & 7.8 \\
\hline De largo plazo & 904954 & 994854 & 990909 & 1033987 & 1155917 & 1299245 & 1624752 & 2059445 & 16.9 \\
\hline Patrimonio & -26870 & 39954 & 49908 & 26885 & -66840 & -111302 & 103177 & -271066 & \\
\hline $\begin{array}{l}\text { Certificados de } \\
\text { aportación }\end{array}$ & 89805 & 93445 & 96958 & 96958 & 96958 & 96958 & 49605 & 49605 & 14.1 \\
\hline $\begin{array}{l}\text { Exceso o } \\
\text { insuficiencia del } \\
\text { patrimonio }\end{array}$ & 144333 & 154101 & 178532 & - & - & - & & & \\
\hline $\begin{array}{l}\text { Resultados } \\
\text { acumulados }\end{array}$ & -305539 & -287786 & -317174 & -261840 & -356502 & -397473 & -119692 & -117091 & 8.0 \\
\hline Otros & 44531 & 80193 & 91592 & 191767 & 192704 & 189213 & 173264 & -203579 & \\
\hline $\begin{array}{l}\text { Total pasivo } \\
\text { y patrimonio }\end{array}$ & 1042560 & 1204735 & 1330281 & 1236837 & 1332037 & 1395197 & 1981374 & 2024183 & 11.2 \\
\hline
\end{tabular}

Fuente: Pemex, Anuario Estadístico 2011 e Informe Anual 2012.

\section{Estado de Resultados}

En los estados de resultados de Pemex se observa que, a lo largo del período, las ventas totales han crecido a una tasa promedio anual de $12 \%$; que la tendencia del costo de ventas es creciente (aumentó a una tasa promedio anual de 17\%); que la relación costo de ventas sobre ventas totales ha pasado de representar 33\% en 2002 a 51\% en 2012; y que los impuestos, derechos y aprovechamientos que paga Pemex crecieron a una tasa promedio anual de $19 \%$, lo que implica que los impuestos avanzaron a una tasa más acelerada que los ingresos de la propia empresa. 


\section{Cuadro II}

\begin{tabular}{|c|c|c|c|c|c|c|c|c|c|c|}
\hline & 2000 & 2005 & 2006 & 2007 & 2008 & 2009 & 2010 & 2011 & 2012 & TCMA\% \\
\hline Ventas totales & 468268 & 928643 & 1062495 & 1136035 & 1328950 & 1089921 & 1282064 & 1558454 & 1646912 & 11.0 \\
\hline En el país & 292880 & 50510 & 546738 & 592048 & 679754 & 596370 & 683853 & 779198 & 867037 & 9.5 \\
\hline De exportación & 175387 & 423534 & 515757 & 542927 & 644418 & 488260 & 592908 & 772965 & 772699 & 13.2 \\
\hline Ingresos por servicios & - & - & - & 1061 & 4778 & 5292 & 5303 & 6291 & 7176 & 23.7 \\
\hline Costo de ventas & 153060 & 361177 & 403106 & 460666 & 654032 & 561135 & 631355 & 778776 & 832491 & 15.2 \\
\hline Rendimiento bruto & 315207 & 567466 & 659389 & 675370 & 674918 & 528786 & 650709 & 779678 & 814421 & 8.2 \\
\hline Gastos generales & 39582 & 68711 & 78041 & 84939 & 103806 & 100509 & 104253 & 107487 & 118101 & 9.5 \\
\hline Gastos de distribución & 12609 & 21911 & 24019 & 24799 & 33962 & 31856 & 33274 & 26710 & 28488 & 7.0 \\
\hline Gastos de administración & 26973 & 46800 & 54022 & 60141 & 69844 & 68653 & 70979 & 80777 & 89613 & 10.5 \\
\hline Rendimiento de operación & 275625 & 498755 & 581348 & 590431 & 571112 & 428277 & 546457 & 861311 & 905339 & 10.4 \\
\hline Otros ingresos (gastos) -neto & 5083 & 11837 & 69742 & 83019 & 197991 & 40293 & 71586 & 189120 & 209019 & 36.3 \\
\hline $\begin{array}{l}\text { Resultado integral de } \\
\text { financiamiento }\end{array}$ & -6652 & -4479 & -22983 & -20047 & -107512 & -15308 & -11969 & & & \\
\hline $\begin{array}{l}\text { Participación en los resultados } \\
\text { de subsidiarias y asociadas }\end{array}$ & - & - & - & 5545 & -1965 & -1291 & 1541 & -811 & 4798 & -1.6 \\
\hline $\begin{array}{l}\text { Rendimiento antes de } \\
\text { impuestos }\end{array}$ & 274057 & 506112 & 628107 & 658948 & 659625 & 451971 & 607613 & 767705 & 905246 & 10.5 \\
\hline $\begin{array}{l}\text { Impuestos, derechos y } \\
\text { aprovechamientos }\end{array}$ & 293768 & 560415 & 582855 & 677256 & 771702 & 546633 & 654141 & 874647 & 902646 & 9.8 \\
\hline Rendimiento neto & -19710 & -76282 & 45252 & -18309 & -112076 & -94662 & -46527 & -106942 & 2600 & \\
\hline Pérdida Integral Total de año ${ }^{\star}$. & & & & & & & & -113387 & -374243 & 230.1 \\
\hline
\end{tabular}

\section{Algunas razones financieras}

En lo que se refiere a las razones de liquidez ${ }^{14}$ es posible apreciar una tendencia decreciente de la Razón Corriente (activo circulante / pasivo circulante). No obstante, en 2012 este indicador se ubicó en 1.35, es decir, Pemex no tuvo dificultades para enfrentar sus obligaciones de corto plazo.

En cuanto a la Prueba ácida, ${ }^{15}$ se tiene que este indicador se encontraba en 1.2 veces; es decir, al igual que en el caso anterior, si bien se ha

\footnotetext{
${ }^{14}$ Miden la capacidad de la empresa para solventar requerimientos de sus acreedores, es decir, permiten determinar la capacidad de la empresa para hacer frente a sus obligaciones de corto plazo.

15 Éste índice (activo circulante excluyendo los inventarios / pasivo circulante), revela la capacidad de pago de una empresa, es decir, mide la capacidad de la empresa para cancelar sus obligaciones corrientes (sin contar con la venta de sus existencias); determina entonces la capacidad de la empresa para cancelar sus obligaciones corrientes, pero sin contar con la venta de sus inventarios.
} 
observado cierto deterioro a lo largo del tiempo, muestra que Pemex no tendría dificultades para hacer frente a sus obligaciones de corto plazo.

\section{Cuadro I2}

\section{Activo Circulante/Pasivo corto plazo}

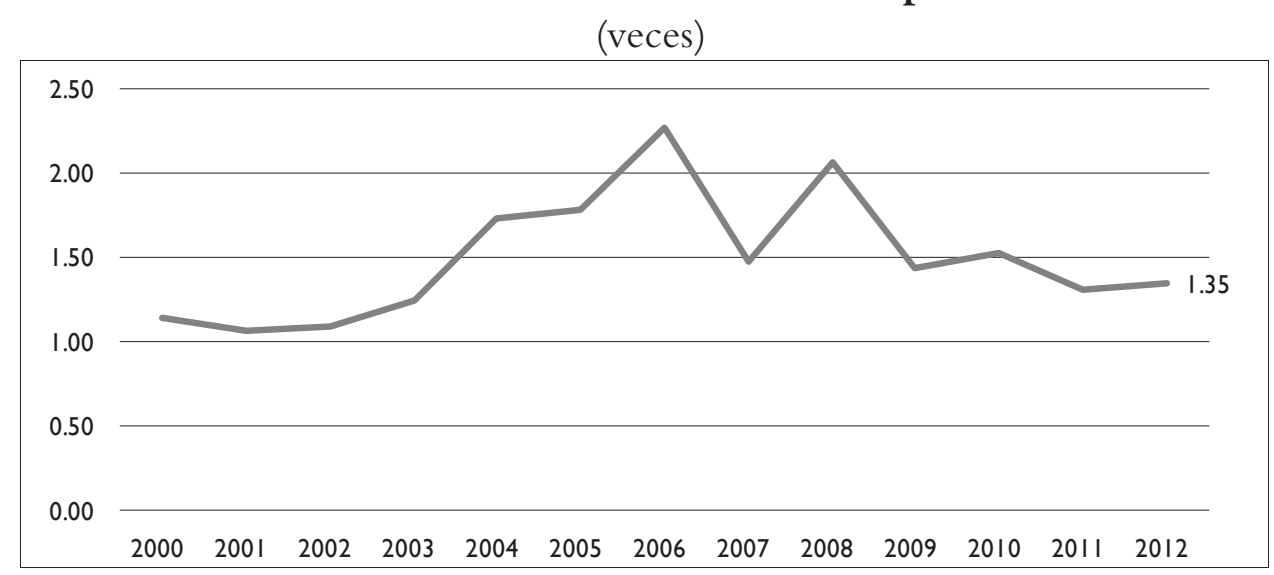

Activo circulante menos Inventarios/Pasivo corto plazo (veces)

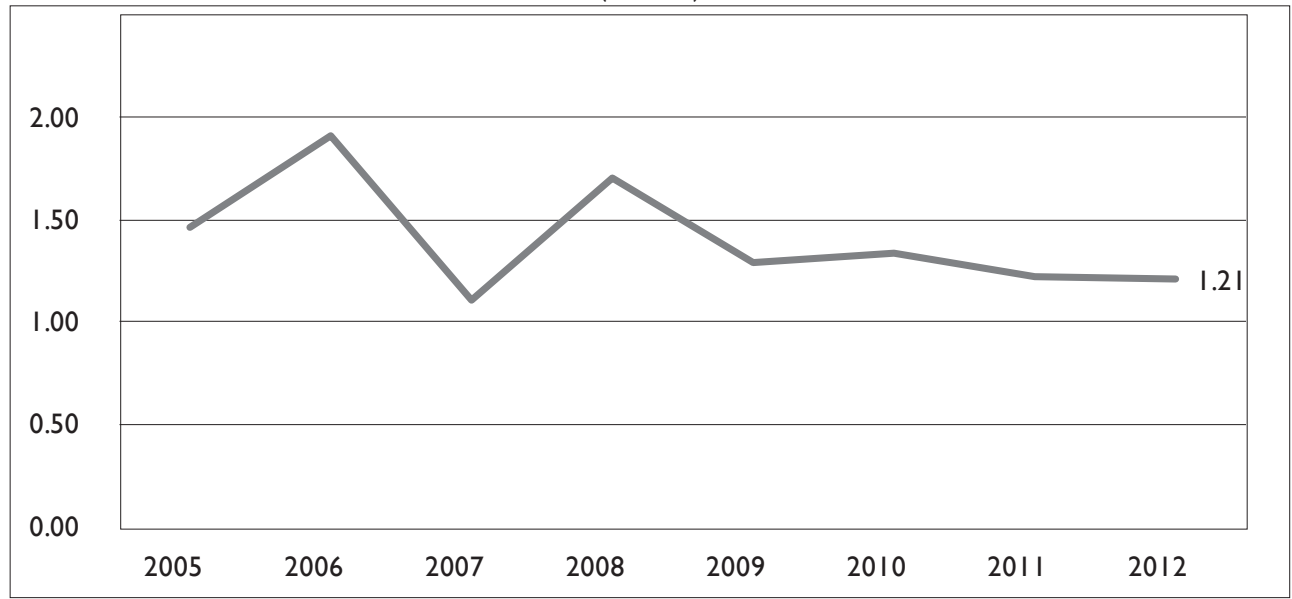

Fuente: elaboración propia con datos de Pemex.

Las razones de eficiencia determinan la productividad con la cual se administran los recursos, para la obtención de los resultados del proceso y el cumplimiento de los objetivos. La relación costo de ventas/ventas totales representó en $201250.5 \%$, la tendencia de este indicador ha ido en aumento, reflejando los crecientes costos de producción de la empresa en los últimos años. 


\section{Cuadro I3}

\section{Costo de Ventas/Ventas Totales}

(porcentaje)

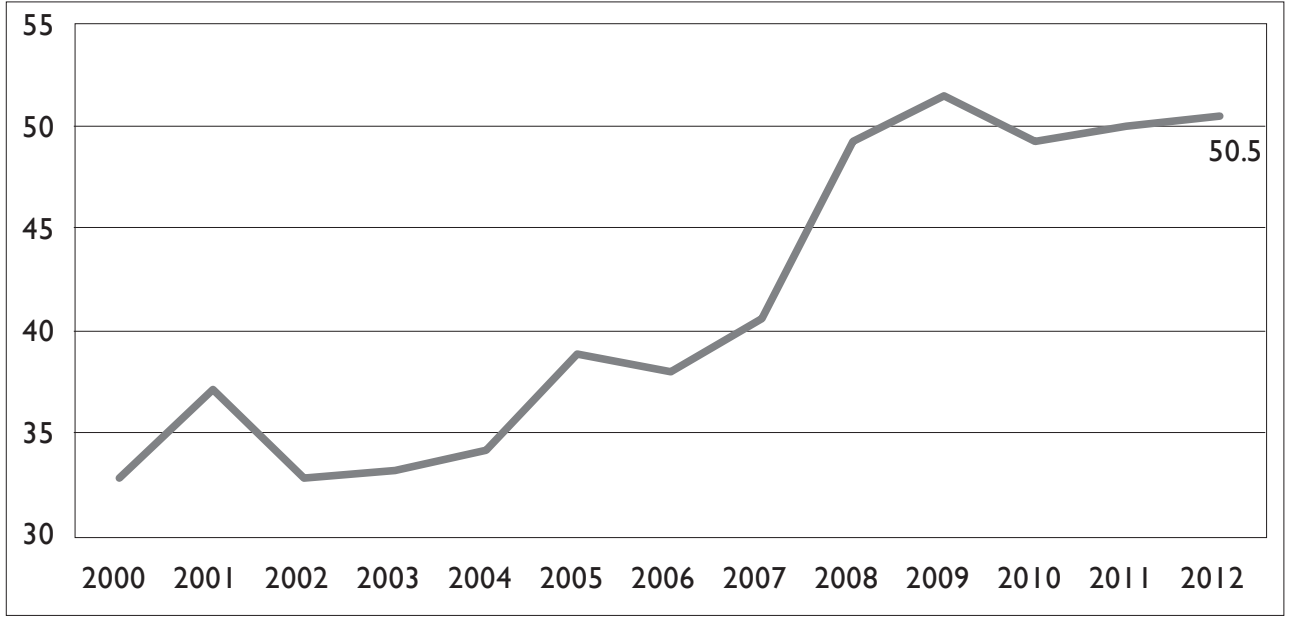

Fuente: elaboración propia con datos de Pemex.

La relación impuestos totales / ventas totales, en el periodo de estudio (2002-2012) promedió 59\%, es decir que más de la mitad de los ingresos por ventas se destinó al pago de impuestos, derechos y aprovechamientos.

\section{Cuadro |4}

\section{Pemex, Impuestos y Derechos sobre Ventas}

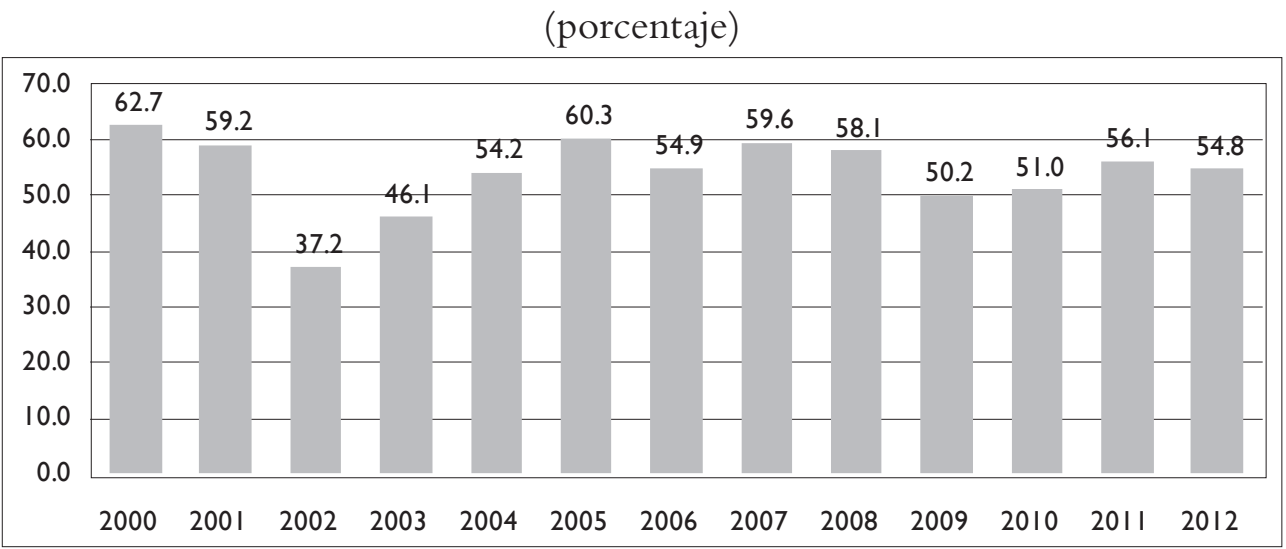

Fuente: elaboración propia con datos de Pemex. 
En cuanto a las razones de endeudamiento, ${ }^{16}$ la relación pasivo total/ activo total para 2012 fue 1.13 veces, esto es, que los pasivos superaron a los activos 13\%. A lo largo del período de estudio se observa un importante deterioro en la situación financiera de Pemex en este rubro.

La relación patrimonio/activo fijo, nos muestra el comportamiento de la inversión de la empresa en activos fijos. La tendencia de este indicador ha sido negativa; para 2002 se encontraba 21\%, y a partir de 2009 es negativa y actualmente tiene un valor de -16 por ciento.

\section{Cuadro I5}

\section{Pasivo Total / Activo Total}

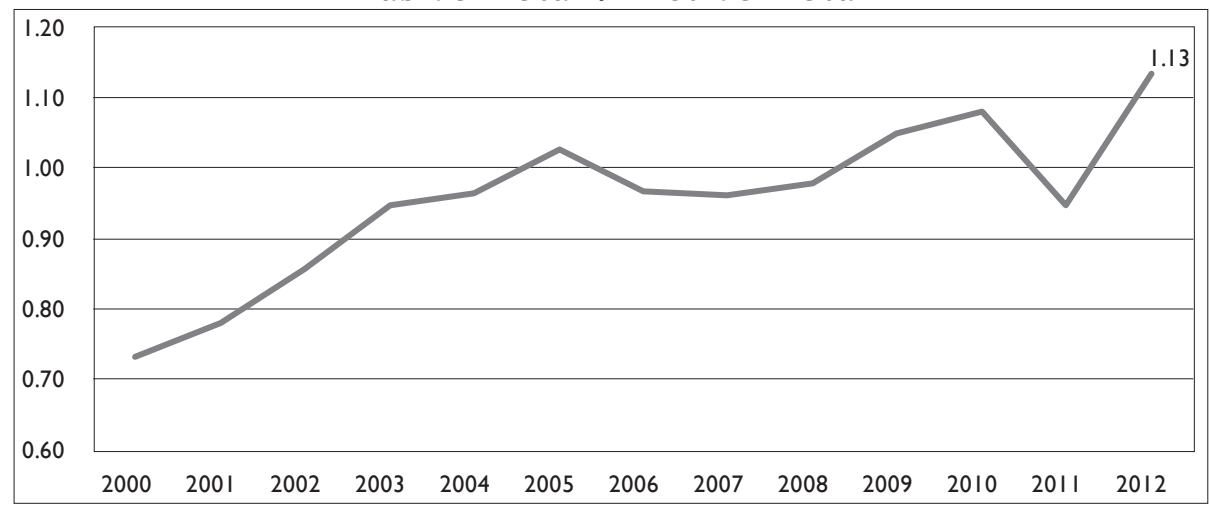

Patrimonio / Activo Fijo

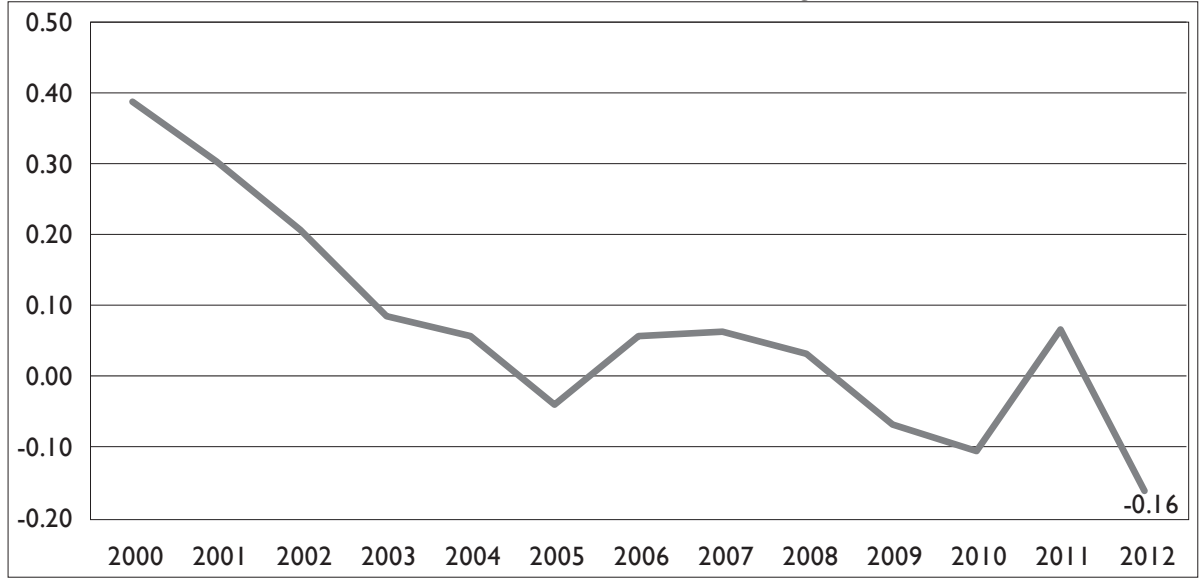

Fuente: elaboración propia con datos de Pemex.

\footnotetext{
16 Estas permiten medir en qué grado participan los acreedores dentro del financiamiento de la empresa. Permiten además, establecer el riesgo que incurren tales acreedores, el riesgo de la empresa y la conveniencia o inconveniencia de un determinado nivel de endeudamiento.
} 


\section{Pasivos laborales}

Un elemento que requiere de especial atención (y que queda fuera del alcance del presente trabajo), es el que se refiere a la evolución de los pasivos laborales de Pemex, los cuales al cierre del ejercicio 2012, excedieron el billón de pesos (por primera vez en la historia de la empresa). Los pasivos de la Reserva para Beneficios a los Empleados (que incluye las pensiones, jubilaciones, gastos médicos de los trabajadores en activo y retirados), entre otros conceptos y que son el resultado de las condiciones pactadas en el contrato colectivo de trabajo con el Sindicato, se ubicó en 1 billón 288 mil 541 millones de pesos, ${ }^{17}$ superaron lo que ganó la empresa por venta y comercialización de combustible y representaron 56\% del total de los pasivos de la Paraestatal. En los últimos cuatro años, los pasivos laborales han crecido a una tasa promedio anual de $31 \%$, representado un riesgo creciente para las finanzas de la empresa.

\section{Experiencias internacionales}

A nivel internacional existen diversos impuestos, derechos y regalías que pagan las empresas petroleras. Los Estados cobran distintas tasas por la explotación se sus recursos, muchas de ellas en la actualidad, son negociables pues dependen de la factibilidad del los proyectos y de las dificultades de extracción de los yacimientos y pueden ser tanto en beneficio del gobierno central como de las provincias donde se encuentran. Existe también la posibilidad de que tanto el Estado como las empresas participen en la explotación de los campos o yacimientos, por lo que deben establecerse puntualmente los impuestos y derechos que deben pagarse por dichas actividades. Las tasas impositivas son muy dispares entre países y de hecho fluctúan entre 0 y $85 \%$ de los ingresos (Rendón et al., 2013). ${ }^{18}$

\footnotetext{
${ }^{17}$ Datos reportados por Pemex, al cuarto trimestre de 2012, Relación con Inversionistas.

${ }^{18}$ En Canadá, por ejemplo, se paga un impuesto sobre la renta federal de $15 \%$ y un impuesto provincial de entre 10 y $16 \%$. También existe un impuesto corporativo de $25 \%$ aunque con posibilidad de reducirlo 15\% por la aplicación de deducciones. Existen además dos incentivos como un impuesto sobre la renta que puede reducirse hasta $10 \%$ por créditos de inversión; y deducciones de hasta $100 \%$ por inversión en investigación y desarrollo. Se imponen además regalías entre el 10 y 45\% que se pagan al dueño del hidrocarburo, por lo general el Estado (Rendón et al., 2013) En Emiratos Árabes, los impuestos se aplican sólo a las compañías extranjeras conforme a contratos de concesión confidenciales. Mientras que en Rusia, las petroleras están sujetas a una tasa impositiva de $20 \%$ sobre las utilidades mundiales proveniente a las actividades de petróleo y gas y se compone de $2 \%$ para los gobiernos federales y $18 \%$ para los locales. Además, se otorgan tratamientos especiales para exploraciones en zonas de muy difícil acceso (Siberia, por ejemplo). En el caso de Estados Unidos, el impuesto federal corporativo a la explotación de recursos naturales es de 35\% sobre los
} 
Economía Informa núm. 385 marzo - abril • 2014 - "

PETROBRAs, por ejemplo, es una sociedad anónima de capital abierto que controla la cadena productiva de petróleo y gas, así como la producción de biocombustibles y otras energías alternativas. En 1997 Brasil promulgó una nueva ley en la que se permitió la presencia de otras empresas petroleras en el país para competir con Petrobras en todas las ramas de la actividad petrolífera. Según esta ley, las actividades de exploración y producción, refinación, transporte, así como la exportación e importación de hidrocarburos y de sus derivados dejaban de ser monopolio de Petrobras y estarían reguladas y fiscalizadas por el gobierno, pudiendo ser ejercidas mediante concesión o autorización, por empresas constituidas bajo las Leyes brasileñas, con sede social en el país.

PETROBRAS es una sociedad de economía mixta, se rige por la Ley de Sociedad por Acciones y cotiza en la bolsa de valores. En dicha empresa existe capital social y privado; sin embargo, el control del estado se establece mediante la propiedad y posesión, como mínimo de 51\% del capital de la sociedad con derecho a voto (Campodónico, H. 2007).

El régimen fiscal aplicable a la industria de petróleo y gas en Brasil incluye un impuesto sobre la renta corporativo a una tasa de 34\%, independientemente de que se trate de una concesión o un contrato de producción compartida, esta tasa se compone de $15 \%$ al que se adicionan 10 puntos porcentuales ciento por utilidades que excedan los 240 mil reales brasileños en un año y un impuesto de contribución social de 9\% (Rendón et al., 2013). ${ }^{19}$

\footnotetext{
ingresos a nivel mundial, incluyendo subsidiarias extranjeras. Dicha tasa puede bajar hasta 20\% para quienes realicen actividades de petróleo y gas con altos costos intangibles de perforación. Se pagan además impuestos locales por la explotación de petróleo y gas así como regalías a los dueños del hidrocarburo (de entre 12.5 y 30\%). En Noruega, los impuestos a la extracción de hidrocarburos gravan áreas específicas establecidas en la Ley con una tasa de 78\% sobre las utilidades operativas de las empresas que realicen esas actividades (28\% corresponde a la tasa corporativa ordinaria y $50 \%$ a una tasa especial) (Rendón et al., 2013).

${ }^{19}$ Los ingresos del gobierno brasileño y terceros se conocen como: Bono firma, que corresponde en una cantidad pagada en una sola exhibición enterada por el ganador de la licitación de una concesión o un contrato de producción compartida; Regalías, para las concesiones se trata de un porcentaje de entre 5 y $10 \%$ sobre el precio del petróleo o gas, mientras que para la producción compartida se aplica un porcentaje del volumen de producción determinado en la licitación; Porcentaje especial de participación, el cual toma en cuenta la productividad y los riesgos y se aplica a las concesiones con tasas que varían de 10 a $40 \%$ basado en tablas progresivas, ingresos brutos, inversiones, costos de operación, depreciación e impuestos; Pago por ocupación (retención del territorio), aplica para concesiones otorgadas respecto de grandes volúmenes de producción; Pago al dueño de la tierra, que para el caso de las concesiones varía de 0.5 a $1.0 \%$ de la producción de petróleo sobre los precios referenciados, y para el caso de la producción compartida se trata de hasta $1.0 \%$ del valor de la producción de hidrocarburos (Rendón et al., 2013).
} 


\section{Cuadro 16}

\section{Distribución Accionaria en Petrobrás}

(porcentaje)

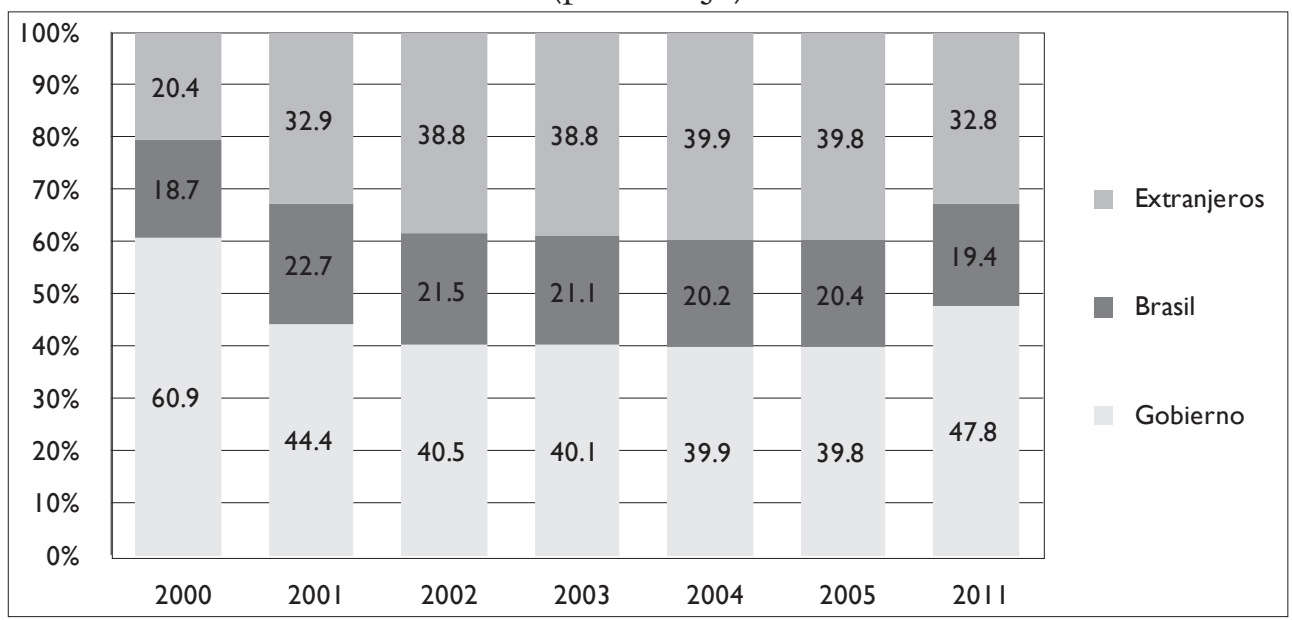

Fuente: tomado de Huerta et al. (2012).

En la actualidad PETROBRAs es considerada como una de las petroleras más exitosas a nivel mundial, pues en poco más de una década pasó del lugar 27 al 3 entre los principales productores. Su desempeño ha sido producto de los siguientes factores (Huerta et al., 2012): Intervención estatal (con una política industrial orientada a la sustitución de importaciones en un contexto de competencia); planificación estratégica basada en un plan de negocios quinquenal; mantener a PETROBRAs fuera del presupuesto federal y contar con un sistema fiscal no confiscatorio; una legislación que otorga amplias facultades de supervisión, fiscalización y sanción a los órganos reguladores (Agencia $\mathrm{Na}$ cional del Petróleo, Gas Natural, y Biocombustibles); capacitación de recursos humanos, desarrollo tecnológico e investigación; un alto contenido nacional en los bienes y servicios que presten las proveedoras; un sistema financiero y una Banca de Desarrollo que financian proyectos productivos; una política de internacionalización; apertura a la inversión privada a través de concesiones y contratos de producción compartida; y capitalización a través del mercado de valores.

Otro factor importante en el crecimiento de Petrobras es su agresiva política de inversión. De acuerdo con los respectivos planes de negocios 20112015, Petrobras invertirá 100 mil millones de dólares más que Pemex con una 
mayor participación en las actividades en relacionadas con la refinería, el gas y la petroquímica.

\section{Cuadro 17}

Petrobras, Plan de Negocios 2011-2015

(224.7 mil millones de dólares)

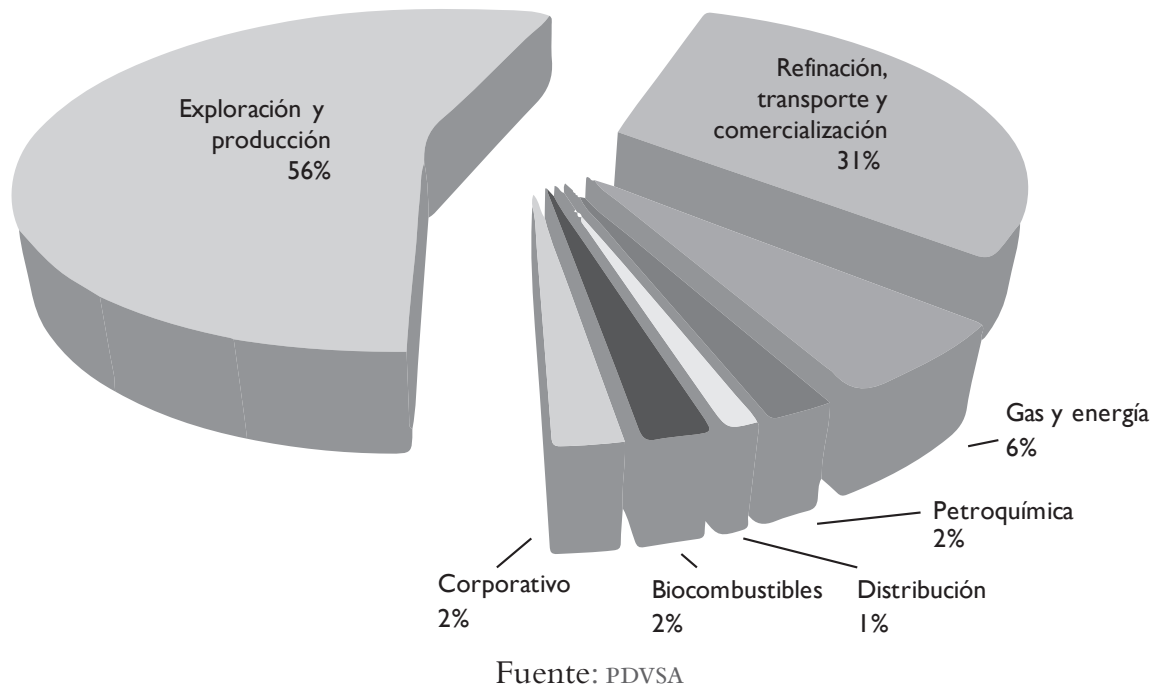

Pemex, Plan de Negocios 2011-2015

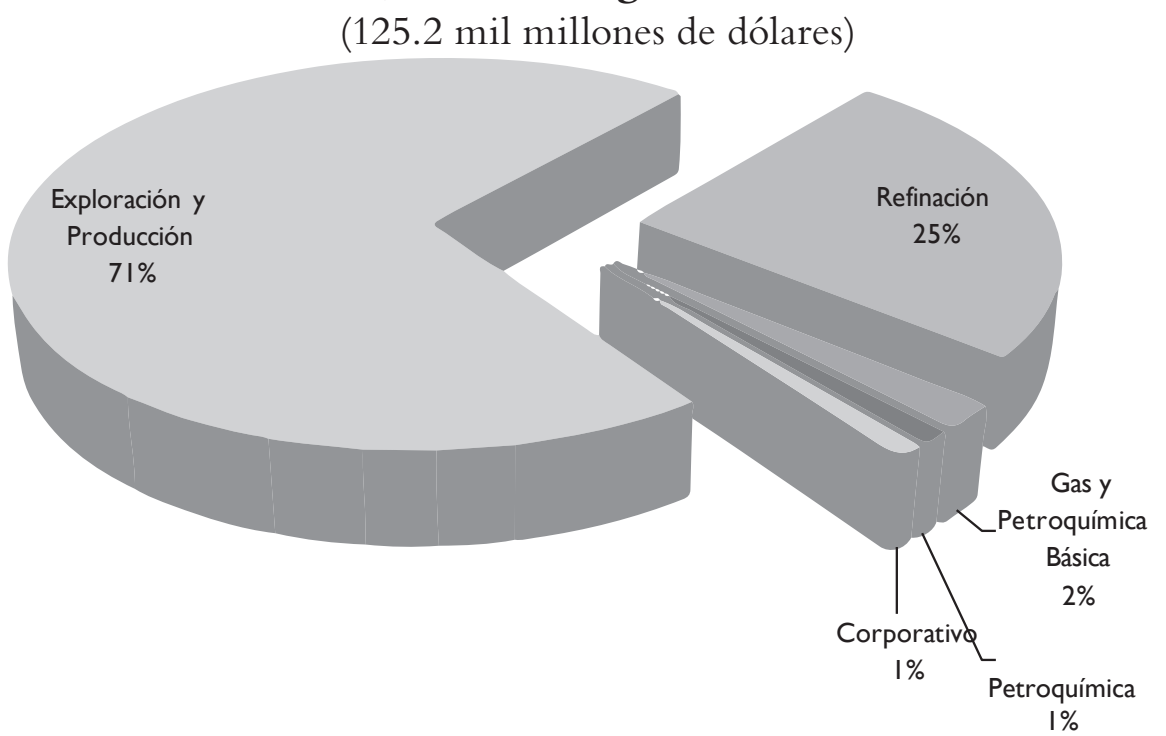

Fuente: Pemex. 
En el caso de Petróleos de Venezuela (PDVsa), ${ }^{20}$ desde los años noventa el Estado permitió la participación de privados para desarrollar proyectos petroleros específicos; principalmente se llevó a cabo bajo tres esquemas:

a) Proyectos de Asociación Estratégica.- En estos proyectos se asociaron seis compañías petroleras extranjeras ${ }^{21}$ con PDVSA, formaron cuatro asociaciones que se encargaron de explotar y mejorar el crudo extra-pesado de la Faja del Orinoco.

b) Convenios de Exploración a Riesgo y Ganancias Compartidas.Bajo estos convenios, privados exploraron y explotaron tres campos petroleros. c) Convenios Operativos.- fueron 32 convenios en los que la petrolera contrató inversionistas extranjeros y venezolanos para la explotación de campos inactivos o de producción marginal, a diferencia de las Asociaciones Estratégicas (el crudo extraído bajo el esquema de Convenios Operativos le pertenecía a PDVSA). ${ }^{22}$

El Plan Siembra Petrolera 2013-2019, ${ }^{23}$ establece que la inversión durante dicho periodo será de aproximadamente 257 mil millones de dólares, de los cuales $81 \%$ estatal y $19 \%$ privada. Del total de inversión, $73.6 \%$ se orientará a las actividades de exploración y producción, $8.6 \%$ a gas y $10.0 \%$ a refinación (el restante $7.7 \%$ se distribuye entre las actividades de comercio y suministro y otras organizaciones).

\footnotetext{
${ }^{20}$ Actualmente tiene reservas probadas de petróleo crudo, equivalentes a 297,570 millones de barriles, y según datos de la OPEP, por sus reservas probadas de petróleo, es la empresa más importante del mundo (en Venezuela se encuentra 17.9\% del petróleo del mundo). Petróleos de Venezuela genera ingresos al gobierno central por cinco vías principales: Regalías, Impuesto sobre la Renta (ISLR), Dividendos, Otros impuestos (IVA, Impuesto de Extracción, Impuesto de Registro de Exportación, Impuesto Superficial e Impuesto de Consumo General) y Aportes al Desarrollo. Es preciso recordar que en Venezuela las empresas petroleras operan bajo el esquema mixto, "Joint Venture", con una participación estatal de por lo menos $50 \%$.

21 Conoco-Philips, Total, Statoil, Chevron, Exxon-Mobil y вP.

22 En 2007 se estableció que las actividades llevadas a cabo hasta entonces por las llamadas Asociaciones Estratégicas, solo podrían realizarse por empresas mixtas, en las cuales el Estado a través de PDVSA y sus filiales, tendría una participación accionaria de por lo menos 60\%. Los Convenios Operativos dieron origen a 21 empresas mixtas en las que PDVSA tiene entre 60 y $75 \%$ del capital social. Los Convenios de Exploración a Riesgo y Ganancias Compartidas, dieron origen a tres empresas mixtas, en las que el Estado tiene participación entre 60 y $73 \%$ del capital social. Actualmente la actividad petrolera en Venezuela se lleva a cabo bajo dichos esquemas de empresas mixtas, aunque la ley establece que la participación de PDVsa en el capital social, sea de cuando menos 50\%, el Estado ha tomado participación de por lo menos $60 \%$.

23 En el Plan Siembra Petrolera 2013-2019 se plasman metas de producción, inversión, proyectos y programas a desarrollar en materia de hidrocarburos.
} 


\section{Cuadro 18}

PDVSA, Plan de Inversiones 2013-2019

(257.0 mil millones de dólares)

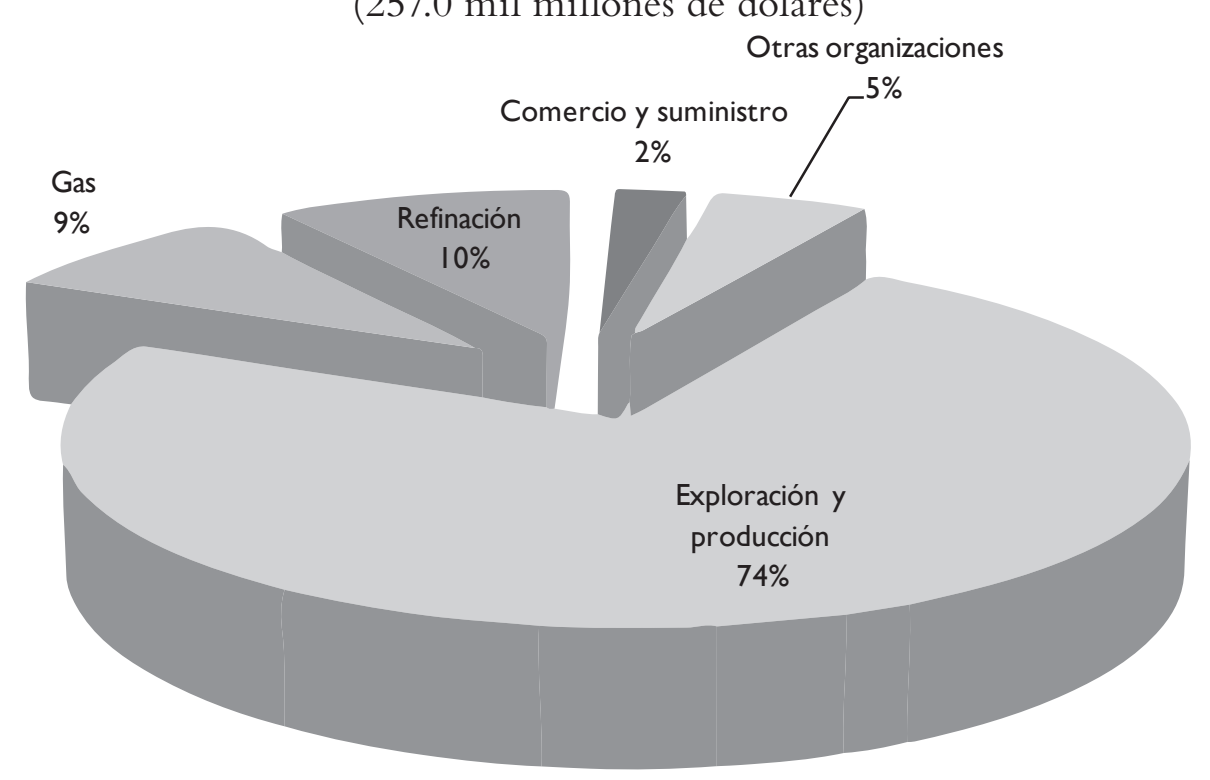

Fuente: PDVsA.

De esta forma, es posible observar que las empresas petroleras más grandes en América Latina además de mantener una importante participación estatal, también incluyen al sector privado nacional y extranjero dentro de sus actividades tanto por la vía de contratos como de concesiones. Es también claro que existe una amplia gama de impuestos que se cobran a las actividades petroleras y que tanto PDVsa como Petrobras tienen planes de inversión más agresivos que Pemex.

\section{Comparativo Internacional}

Si se hace un comparativo de algunos de los principales indicadores operativos de Pemex con otras compañías petroleras del mundo, es posible encontrar resultados de gran relevancia. Por un lado, en lo que se refiere al margen neto entre diversas compañías petroleras mundiales, es posible apreciar que en 2012 Pemex fue la empresa que reporta menores utilidades como proporción de sus ingresos $(0.2 \%)$, mientras que PETROBRAS y PDVSA reportaron 7.6 y $3.4 \%$, respectivamente. 


\section{Cuadro 19}

\section{Margen Neto, Comparativo Internacional 2012}

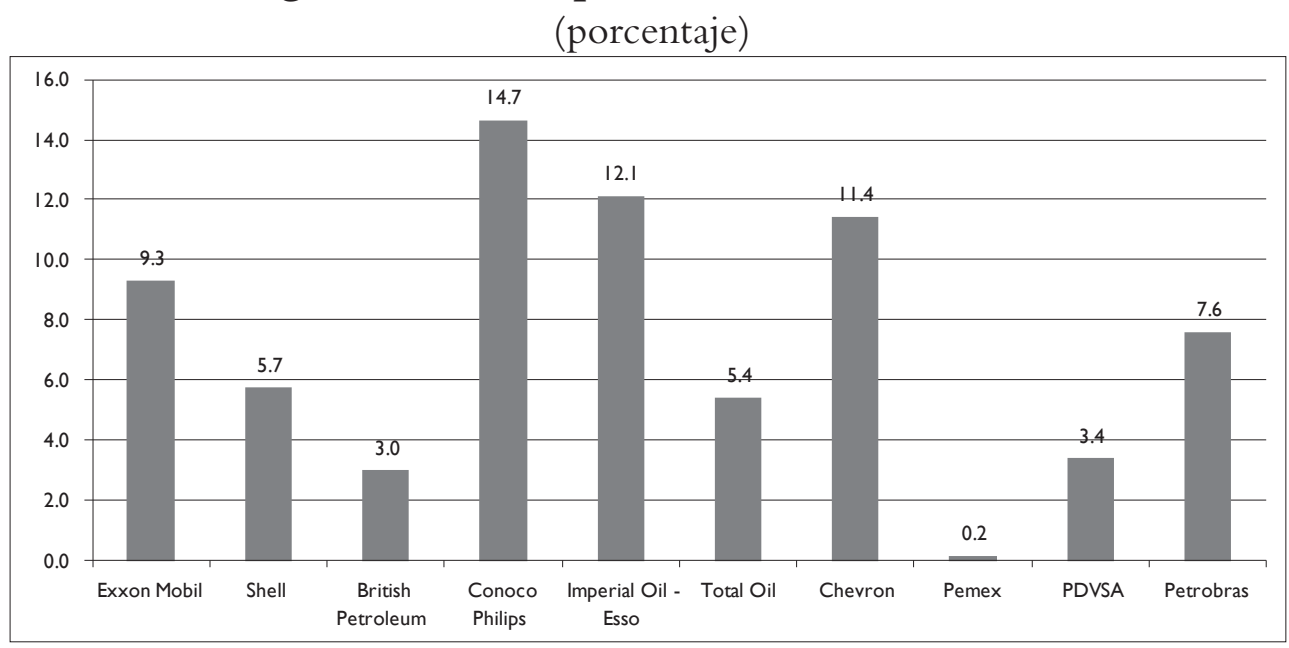

Fuente: elaboración propia con datos de los estados financieros de las distintas compañías que se reportan (2012).

Por otro lado, en lo que se refiere a la carga fiscal, en el siguiente cuadro es posible observar que para Pemex esta representa $54.8 \%$ de las ventas, el mayor porcentaje de entre las empresas de la muestra. En tanto que para el caso de Venezuela y Brasil fue de 34.0 y $2.7 \%$, respectivamente.

\section{Cuadro 20}

Impuestos / Ventas, 2012

(porcentaje)

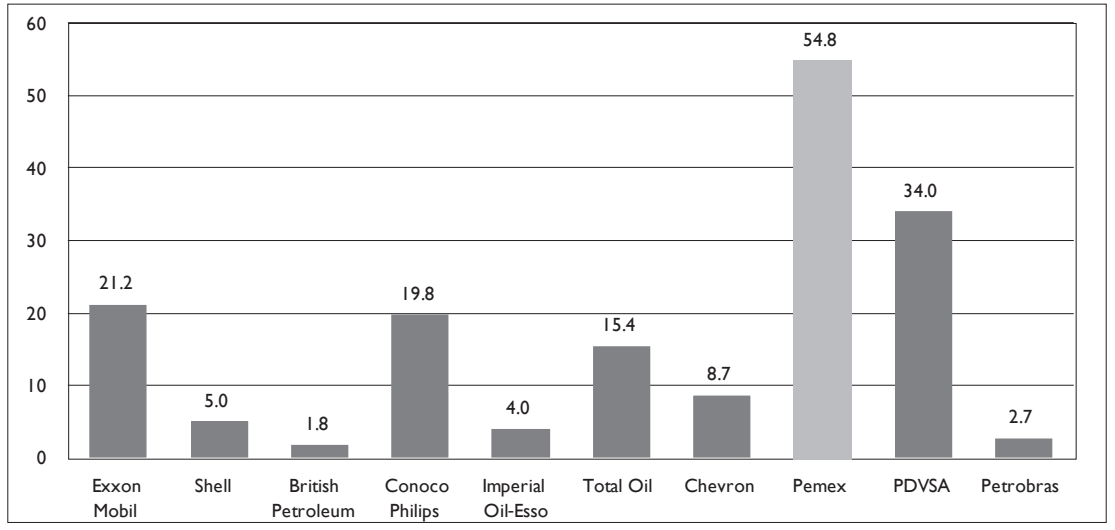

Fuente: elaboración propia con datos de los estados financieros de las compañías que se reportan(2012). 
Pese a lo que pueda pensarse al observar los dos indicadores anteriores, operativamente Pemex no es una empresa ineficiente, pues si se analizan los márgenes operativos de las empresas petroleras de la muestra, la paraestatal mexicana resultó ser la más rentable de las compañías; esto es, aún con los crecientes costos de ventas y administrativos con las que comúnmente se le caracteriza, reporta mejores resultados que los de otros importantes competidores internacionales. Por lo tanto, lo que Pemex requiere es una carga fiscal acorde a lo que ocurre en otras latitudes, pues se trata de una empresa competitiva a nivel internacional.

\section{Cuadro 21}

Margen Operativo, 2012

(porcentajes)

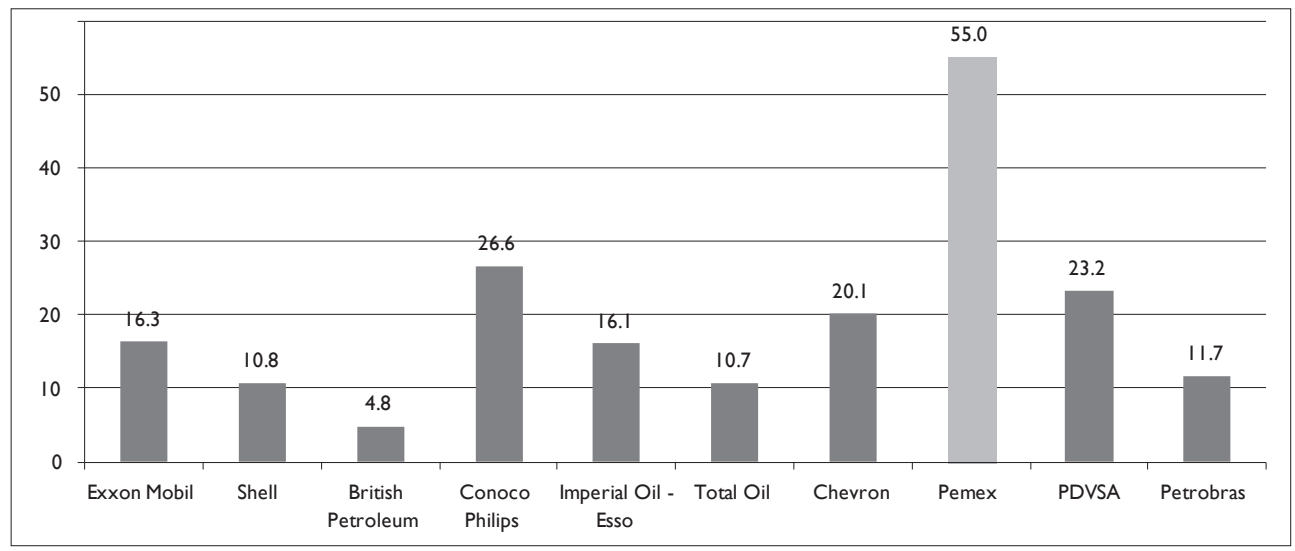

Fuente: elaboración propia con datos de los estados financieros de las compañías que se reportan(2012).

\section{Aspectos Relevantes de las Propuestas de Reforma Energética en México}

A continuación se describen brevemente las iniciativas de reforma que, en materia energética, presentaron las tres principales fuerzas políticas representadas en el Congreso con el propósito de modernizar y dar impulso tanto a la industria petrolera como a la eléctrica. 


\section{V.I Propuesta del Ejecutivo Federal}

El Ejecutivo estableció que en materia de Exploración y Extracción el país enfrenta importantes retos, pese a que Pemex ha destinado mayores recursos a la inversión, la producción de hidrocarburos no ha revertido su tendencia decreciente. Además, de acuerdo con la Iniciativa, México cuenta con reservas probadas para 10 años de producción, ubicadas mayoritariamente en aguas someras del Golfo de México, lo cual otorga al país un margen de tiempo suficiente para confirmar la existencia de reservas y recursos prospectivos de nuevos yacimientos, y eventualmente convertirlos en producción. Sin embargo, estos recursos están localizados en yacimientos de gran complejidad que demandan capacidades de ejecución e inversión que sólo se pueden alcanzar con la concurrencia de diversas empresas petroleras. Otro de los retos identificados era el de aumentar el factor de recuperación de los campos maduros, lo cual requiere del uso intensivo de técnicas de recuperación mejorada con lo que el país no cuenta.

De acuerdo con la Iniciativa, en el ámbito internacional, la práctica más extendida es que las empresas realicen operaciones en aguas profundas con esfuerzos compartidos, por lo que Pemex debería tener la oportunidad de actuar en igualdad de condiciones.

Por otro lado, en lo que se refiere a la producción nacional de petróleo y gas, esta resulta insuficiente pues las importaciones de gas natural, gasolinas, diésel y petroquímicos son crecientes, por lo que existe el riesgo de que México se convierta importador neto de hidrocarburos en el corto plazo.

En el caso de la petroquímica, el diagnóstico presentado apuntaba a que las importaciones netas representan aproximadamente el doble de la producción nacional, que el transporte de estos productos es ineficiente, y que existe una limitada capacidad de refinación y transformación en relación a la producción. $^{24}$

Se reconoce también que las importaciones de gas natural pasaron de representar 3\% en 1997 a 33\% en 2012, mientras que las de gasolinas pasaron del 25 a 49\%. Además, en noviembre de 2012, el sistema de gasoductos alcanzó su tope máximo de transporte, limitando el volumen de importaciones a través de ductos y ocasionando problemas de abasto.

\footnotetext{
24 En 2012, se producían diariamente 2.5 millones de barriles de crudo y sólo se refinaron 1.2 millones al día; se importó la mitad de las gasolinas y una tercera parte del diésel que se consumen en el país.
} 
Economía Informa núm. 385 marzo - abril • 2014 - "

\section{Objetivo de la Reforma}

El objetivo central de la reforma propuesta por el Ejecutivo Federal era permitir un abasto suficiente y a precios competitivos, de los combustibles que requieren los consumidores residenciales, comerciales e industriales. Se pretendía además, Introducir esquemas contractuales eficientes para la exploración y extracción de petróleo y gas natural con la participación de particulares en refinación, petroquímica, transporte y almacenamiento de productos petroleros, por lo que se propuso la colaboración de la iniciativa privada mediante formas distintas a la concesión a través de dos esquemas: 1) Contratos eficientes para la exploración y extracción celebrados con el Ejecutivo Federal, y 2) Participación de terceros en toda la cadena de valor de los hidrocarburos, a través de autorización expresa del Gobierno Federal.

La propuesta de reforma del Ejecutivo pretendía:

1) Mantener la propiedad de la Nación sobre los hidrocarburos en el subsuelo, sólidos, líquidos y gaseosos en todo momento;

2) Mantener la prohibición de otorgar concesiones, al basarse en la conducción decidida e irrenunciable de las actividades del sector por parte del Estado, en el entendido de que sólo éste puede disponer de los recursos del subsuelo; 3) Incorporar contratos, que celebre el Ejecutivo Federal, con organismos y empresas del Estado y terceros que permitan expandir y hacer más eficientes las actividades de exploración y extracción de hidrocarburos, y

4) Autorizar, a partir de permisos otorgados por el Ejecutivo Federal, la participación de terceros en refinación, transporte, almacenamiento y distribución de hidrocarburos sin que se ponga en riesgo la propiedad de nuestros recursos.

En materia de hidrocarburos las propuestas eran las siguientes:

1. Eliminar la prohibición de que el Estado celebre contratos para la explotación de hidrocarburos ${ }^{25}$

2. Sustraer de las áreas estratégicas del Estado a la petroquímica básica y dar certeza constitucional para que el procesamiento de gas natural, la refinación del petróleo, el transporte, almacenamiento, distribución y comercialización de dichos productos y sus derivados, puedan ser realizados tanto por organismos del Estado, como por los sectores social y privado, a través de los permisos que otorgue el Ejecutivo Federal. ${ }^{26}$

\footnotetext{
${ }^{25}$ La Iniciativa consideraba que la participación de particulares, a través de contratos, podría aportar las altas inversiones, así como recursos tecnológicos y experiencia. Por lo que eliminaba del artículo 27 Constitucional la restricción que impedía al Estado la utilización de contratos en sus actividades de explotación de hidrocarburos pero mantenía la prohibición de otorgar concesiones que confieran derechos sobre los recursos naturales a los particulares. 
El artículo 28 Constitucional consideraba dentro de las áreas estratégicas las funciones que el Estado ejerciera en petroquímica básica, por lo que se propuso reformarlo para suprimir a la petroquímica básica como área estratégica y señalar expresamente que tratándose de petróleo y demás hidrocarburos se realizaría conforme a lo dispuesto por el párrafo sexto del artículo 27 de la Constitución, es decir, la función de explotar los hidrocarburos del subsuelo, sería llevada a cabo en la forma que determine la Ley Reglamentaria, la cual establecería las condiciones bajo las cuales puedan concederse permisos a los particulares para llevar a cabo estas actividades, así como la regulación a la que estarían sujetos en su operación.

\section{Beneficios esperados}

El Ejecutivo Federal esperaba que, de concretarse las reformas, se permitiría al país consolidar un modelo de hidrocarburos sostenible en el largo plazo y alcanzar los siguientes objetivos:

- Lograr tasas de restitución de reservas probadas de petróleo y gas superiores a $100 \%$.

- Incrementar la producción de petróleo, de 2.5 millones de barriles diarios actualmente, a 3 millones en 2018, así como a 3.5 millones en 2025.

- En el caso del gas natural, la producción aumentaría de los 5 mil 700 millones de pies cúbicos diarios que se producen actualmente, a 8 mil millones en 2018, así como a 10 mil 400 millones en 2025.

- Propiciar una mayor integración en la cadena de valor a partir de la extracción de los hidrocarburos, lo que permitirá un abasto suficiente de gasolinas, gas metano y gas licuado de petróleo, a precios competitivos.

El incremento en la inversión y la producción incidirá favorablemente en el crecimiento del PIB y en la generación de empleos, al mismo tiempo que permitirá la obtención de recursos fiscales adicionales.

Por otro lado, la Iniciativa del Ejecutivo Federal, establecía la necesidad de modificar el régimen fiscal de la paraestatal, lo que implicaría un cambio de paradigma con un pago de derechos más bajo para que fuera reinvertido o transferido al presupuesto federal. Este nuevo esquema haría que Pemex tuviera un tratamiento fiscal comparable al de otras empresas petroleras en el resto del mundo.

convendría complementar a Pemex en actividades de refinación, de petroquímica y de transporte. 
Economía Informa núm. 385 marzo - abril • 2014 - "

\section{Sector eléctrico}

En materia de electricidad, la iniciativa del Ejecutivo reconoce la necesidad de contar con acceso a fuentes de energía confiables, limpias y a precios competitivos. Sin embargo, enfatiza que esta situación se da en un contexto en el que las finanzas de la Comisión se han tornado endebles. ${ }^{27}$

Por lo anterior, identifica las siguientes áreas de oportunidad: Falta de competitividad de las tarifas eléctricas; limitaciones y altos costos en la generación de energía; limitaciones en la transmisión y distribución; conflictos de interés y limitaciones en la transición energética. Además considera que las tarifas de la CFE no son competitivas a nivel internacional, pues establece que aún con subsidio, nuestras tarifas son $25 \%$ superiores a las de Estados Unidos. Existe también una oportunidad importante de reducir costos y mejorar las finanzas de la CFE mediante la reducción de las pérdidas de energía.

De acuerdo con la iniciativa, dado que los resultados financieros de la CFE no son sostenibles y que el alza de tarifas no es una opción para restaurar la salud financiera de la empresa, es indispensable reducir los costos de producción.

Aunado a lo anterior, el país se tiene el objetivo de avanzar en la transición energética. De acuerdo con la Ley General de Cambio Climático, México debe reducir las emisiones de gases de efecto invernadero 30\% para el año 2020 y 50 \% para el 2050 (respecto de las emisiones del año 2000), así como promover que al menos $35 \%$ de la generación provenga de fuentes limpias en 2024.

La Iniciativa del Ejecutivo establecía que el Sistema Eléctrico Nacional debe contar con un diseño adecuado para impulsar el aprovechamiento de las energías renovables y que la CFE no cuenta con la flexibilidad necesaria para integrar de manera eficiente las energías renovables a gran escala. Asimismo, establece que las mejores prácticas internacionales destacan la importancia de contar con una entidad independiente que realice la planeación y la operación de la red de transmisión, así como el despacho de la energía, es decir, que controle la operación del Sistema Eléctrico Nacional.

De esta forma, los objetivos principales de la Reforma son: reducir los costos del servicio eléctrico; sentar las bases para la organización de un sistema eléctrico nacional basado en principios técnicos y económicos; plantear

27 En 2012, la Comisión Federal de Electricidad (CFE) presentó un déficit financiero de 77 mil millones de pesos, de los cuales, una parte se subsanó con la exención del pago del aprovechamiento por el uso de patrimonio del Estado; no obstante, CFE tuvo que absorber 33.4 mil millones de pesos mediante decrementos de su patrimonio. De acuerdo con estimaciones de la propia Comisión, de continuar las tendencias actuales, el patrimonio neto de la empresa será negativo al cierre de 2014. 
el desarrollo del sector basado en la participación conjunta de la CFE y de particulares; y fortalecer las facultades del Estado para regular el desarrollo del sector e imponer a los participantes obligaciones de interconexión, tarifas, servicio universal y electrificación.

Para el Ejecutivo federal, a diferencia de los hidrocarburos, la electricidad no es un recurso natural, por lo que el interés del Estado no es la propiedad sobre la energía, sino que ésta llegue a mejores precios a las familias mexicanas e impulse la competitividad del país. Por lo que planteaba abrir el mercado de generación para disminuir los costos, sin que el Estado pierda la rectoría en el control del sistema eléctrico nacional y la exclusividad de transmitir y distribuir la energía.

En términos generales la reforma consiste en:

- Reformar el Artículo 27, para permitir la participación de particulares en la generación de electricidad.

- Reservar para el Estado la exclusividad y el control del Sistema Eléctrico Nacional, así como el servicio público de las redes de transmisión y distribución.

- Fortalecer a CFE mediante una mayor flexibilidad operativa y organizacional, que ayudará a reducir costos

- Reforzar las facultades de planeación y rectoría de la Secretaría de Energía y de la Comisión Reguladora de Energía.

- Favorecer la inversión en el desarrollo tecnológico y la adopción de fuentes de energía menos contaminantes y de bajo costo.

El Ejecutivo espera los siguientes beneficios de la aprobación de la Iniciativa: una generación más eficiente, limpia y económica; la creación de un mercado competitivo que eleve la capacidad de generación; un proceso de interconexión que aumente la transparencia y eficiencia; certidumbre jurídica a los proyectos de participación privada; reducción de las tarifas eléctricas.; desarrollo de nuevos proyectos de inversión, particularmente de energías limpias; profundización del cambio tecnológico y reducción de las emisiones de gases de efecto invernadero; eficiencia y desarrollo de proyectos de generación; sustitución de generación a través de combustóleo y diésel por generación limpia y de gas natural; aumento en la transparencia y eficiencia en el otorgamiento de acceso a la red de transmisión, múltiples desarrolladores y aumento en la capacidad; certidumbre jurídica a los proyectos de participación privada; despacho eléctrico operado por un organismo público de manera imparcial e independiente y con tarifas transparentes fijadas de manera 
Economía Informa núm. 385 marzo - abril • 2014 - "

eficiente y reducción significativa de pérdidas de 10\% o más en distribución como resultado de la reestructuración del sector.

\section{V.2 Iniciativa en Materia de Reforma Energética del PAN}

El pasado 31 de julio, el PAN presentó ante la Comisión Permanente del Congreso de la Unión, la Iniciativa con proyecto de Decreto que reforma, adiciona y deroga diversas disposiciones a los artículos 25, 27 y 28 de la Constitución Política de los Estados Unidos Mexicanos.

Las reformas planteadas por el PAN están encaminadas a:

- Otorgar al Estado elementos para el aprovechamiento de los recursos naturales.

- Atraer nuevas tecnologías e inversiones.

- Acabar con los monopolios estatales.

- Impulsar el desarrollo de energías limpias, baratas y eficientes.

- Reducir el costo de la energía eléctrica.

- Ofrecer a los ciudadanos mejores condiciones de vida en un ambiente competitivo que detone nuevas fuentes de trabajo.

- Consolidar nuestra independencia energética.

Esta Iniciativa considera que a contra corriente de la tendencia internacional, México ha cerrado las puertas a cualquier tipo de inversión privada en la cadena productiva de los hidrocarburos, colocando a Pemex en una situación de desventaja, pues no cuenta con la capacidad económica suficiente para adquirir y desarrollar la tecnología que le permita la exploración de hidrocarburos en aguas profundas y potencializar el uso del gas natural.

La Iniciativa del PAN reconoce que en los últimos 10 años, Pemex ha registrado una caída en la producción de prácticamente todas las actividades operativas, la cual ha estado asociada al agotamiento de los yacimientos que desde hace décadas se han venido explotando. Aunado a lo anterior se encuentra la limitada capacidad de transporte, almacenamiento y distribución vía ductos, impide el acceso a la abundante oferta de gas natural y a sus precios históricamente bajos, pues la saturación del Sistema Nacional de Ductos no permite importar todo el combustible requerido para abastecer la demanda nacional.

Las modificaciones propuestas al artículo 25, incluían el tema ambiental que en el desarrollo económico al establecer que correspondería al Estado la rectoría del desarrollo nacional para garantizar que éste sea integral, sustentable y con bajas emisiones de gases y compuestos de efecto invernadero, que 
fortalezca la Soberanía de la Nación y su régimen democrático y que, mediante la competitividad, el fomento del crecimiento económico y el empleo y una más justa distribución del ingreso y la riqueza, permita el pleno ejercicio de la libertad y la dignidad de los individuos, grupos y clases sociales, cuya seguridad protege esta Constitución.

Se propuso también reformar el sexto párrafo del Artículo 27 Constitucional para eliminar la prohibición de otorgar concesiones o contratos para la exploración y producción de petróleo e hidrocarburos, y garantizar que dichos recursos son y seguirán siendo propiedad de la Nación. La reforma implicaría dotar a Pemex de un gobierno corporativo eficiente y con plena libertad para determinar sus esquemas de inversión, coinversión y desarrollo de tecnologías, al tiempo de permitir a otras empresas, nacionales o extranjeras, participar en la exploración y producción de petróleo e hidrocarburos, a través de procesos de licitación pública. Tanto Pemex como los nuevos operadores pagarían derechos por el petróleo y los hidrocarburos que extraigan, cuya administración estará a cargo del Fondo Mexicano del Petróleo.

Por otra parte, en lo que se refiere al sector eléctrico nacional, la Iniciativa propone fortalecerlo a través de una mayor competencia en los procesos de generación y comercialización de la electricidad, con el fin de atender eficazmente las necesidades de la población. La propuesta reformaba el sexto párrafo del Artículo 27 constitucional para eliminar la restricción de otorgar concesiones a los particulares en los procesos de generación, transmisión, distribución y abastecimiento de energía eléctrica que tenga por objeto la prestación del servicio público.

Esta reforma implicaba, además de eliminar las restricciones vigentes a la entrada de nuevos operadores, la separación de las actividades de generación, transmisión y distribución y comercialización de energía eléctrica que actualmente realiza la CFE.

La propuesta del PAn planteaba también la modificación del Artículo 28 Constitucional para incorporar al Fondo Mexicano del Petróleo, la Comisión Reguladora de Energía y a la Comisión Nacional de Hidrocarburos como órganos reguladores del sector energético del país. El Fondo sería un órgano autónomo con personalidad jurídica y patrimonio propios que administraría la renta petrolera, recibiría los derechos de los recursos petroleros y retendría y enteraría a la SHCP el porcentaje correspondiente. ${ }^{28}$

\footnotetext{
28 La Iniciativa pretendía disminuir la dependencia fiscal de los recursos petroleros y eliminar el pasivo laboral de Pemex en un periodo no mayor a diez años. Se propuso también elevar a rango constitucional a la Comisión Nacional de Hidrocarburos ( $\mathrm{CNH}$ ) a efecto de que regule el otor-
} 
Economía Informa núm. 385 marzo - abril • 2014 - "

En los Artículos Transitorios sobresalen las propuestas de que Pemex y CFE cuenten con autonomía de gestión y organización, y no serán incluidos en el Presupuesto de Egresos de la Federación; por lo que la Cámara de Diputados sólo aprobaría el techo financiero y nivel de capitalización al que deberá sujetarse.

También se propone un plan de adaptación a diez años tendiente a disminuir la dependencia fiscal de los recursos petroleros y a eliminar el pasivo laboral de Pemex. Establece además que el otorgamiento de concesiones será a través de licitaciones internacionales abiertas a empresas públicas, privadas y asociaciones público-privadas, nacionales o extranjeras, y plantea la ejecución de un plan de sustitución del uso del combustóleo y otros combustibles con alta emisión de gases efecto invernadero en la generación de energía eléctrica, por gas natural.

\section{V.3 Iniciativa en Materia de Reforma Energética del PRD}

El 20 de agosto de 2013, la fracción parlamentaria del PRD, presentó ante la Cámara de Diputados, la Iniciativa con proyecto de decreto por el que se reforman, derogan y adicionan diversos ordenamientos en materia de reforma integral del sector energético nacional.

Esta propuesta no reformaba la Constitución ni transfería recursos de la Nación, o sus rentas, a particulares; sino que buscaba que Pemex y la CFE fortalecieran su aporte al desarrollo nacional, para detonar la inversión, el desarrollo industrial y la creación de empleo.

Los ejes estratégicos de la propuesta eran: Cambio en el régimen fiscal de Pemex; autonomía presupuestal y de gestión; fortalecer a la SENER y a la CNH; acceso equitativo a la energía; convertir al Fondo de Estabilización de Ingresos Petroleros en un organismo financiero; impulsar la investigación y

gamiento, autorización y revocación de permisos o concesiones para la generación, transmisión, distribución, comercialización, suministro y venta de energía eléctrica que realicen el Estado y los particulares; así como la refinación, procesamiento, distribución, transporte y almacenamiento del petróleo y de los hidrocarburos, conforme a las disposiciones, requisitos y condiciones que prevea la legislación secundaria.

En lo que se refiere a la sustentabilidad ambiental, la reforma establecería como principio constitucional, el uso sustentable de todos los recursos naturales. El Estado tendría la obligación de asegurar el uso eficiente y sustentable de los recursos energéticos, y desarrollaría, para tal efecto, las estrategias y programas integrales de mitigación y adaptación al cambio climático. Asimismo, las empresas del sector tendrían la obligación de incorporar mejores prácticas de eficiencia en el uso de la energía y disminución de las emisiones de gases y compuestos de efecto invernadero. 
el desarrollo; transición energética, cuidado del medio ambiente y desarrollo sustentable.

Los objetivos que la Iniciativa pretende alcanzar eran los siguientes:

- Mejorar el acceso, calidad y precios de los energéticos.

- Mantener la propiedad de los hidrocarburos para la Nación y la responsabilidad del Estado en áreas estratégicas de petróleo, gas, petroquímica y electricidad.

- Establecer la obligación de Pemex de reponer 100\% las reservas probadas de hidrocarburos.

- Transparentar la participación de yacimientos en la renta nacional.

- Garantizar el uso sustentable de los recursos no renovables e impulsar la transición a tecnologías renovables limpias.

- Mejorar los márgenes de seguridad energética.

- Transparentar los subsidios.

- Preservar los derechos de los trabajadores

De manera específica, en materia de política de hidrocarburos la Iniciativa planteaba: Moderar la extracción de petróleo crudo, para dar tiempo a la reposición de reservas y a la expansión de la infraestructura local de transformación; recuperar la producción petroquímica, mediante el establecimiento de acuerdos de largo plazo para el abasto de insumos y fórmulas de precios, que fomenten la inversión en eslabones intermedios y finales de las cadenas industriales; fortalecer el capital tecnológico de Pemex mediante la formación de los trabajadores, técnicos e investigadores de alto nivel; aumentar la producción de gas natural, cuya rentabilidad debe conducir a reafirmar la exclusividad del estado en su explotación y a reorganizar estructuralmente a Pemex para establecer una estrategia de financiamiento específico que lleve a desarrollar las potencialidades del país, incluyendo los recursos de lutitas; prohibir la quema de gas asociado. El valor económico y ambiental del gas natural obliga a lograr un aprovechamiento integral de las disponibilidades; establecer un Fondo para los Excedentes Petroleros, cuyos recursos servirán para compensar caídas en el precio del petróleo y acumular recursos para la inversión.

En lo que se refiere a los objetivos de la política de electricidad, la Iniciativa del PRD propuso: ${ }^{29}$

\footnotetext{
29 Esta Iniciativa plantea la reforma de 11 ordenamientos vigentes (Ley de Petróleos Mexicanos; Ley Reglamentaria del Artículo 27 Constitucional; Ley Federal de Presupuesto y Responsabilidad Hacendaria; Ley Federal de Derechos; Ley Orgánica de la Administración Pública Federal; Ley
} 
Economía Informa núm. 385 marzo - abril • 2014 =

- Que todos los habitantes del país dispongan del fluido eléctrico, con máxima calidad y mínimo costo.

- Que el aparato productivo disponga de un abasto en electricidad continuo, estable y a precios competitivos, para aumentar su productividad y alentar el desarrollo económico.

- Fortalecer la cadena de generación, transmisión, distribución y comercialización, para mejorar la calidad del suministro de energía eléctrica, y ampliar los mecanismos de atención a los usuarios del servicio y de apoyo para el ahorro de energía.

- Desarrollar tecnologías de generación de bajo costo y bajo impacto ambiental, tales como la cogeneración, de manera obligada por CFE en instalaciones de Pemex.

- Tarifas equitativas, sustentadas en criterios técnicos y económicos, formuladas por nivel de tensión y tipo de suministro, y sin favorecer o discriminar a sectores específicos.

- Ampliar el uso de fuentes renovables de energía para generar electricidad, establecer cuotas de participación para la nueva generación eléctrica y aplicar mecanismos compensatorios para que éstas compitan efectivamente con las fuentes tradicionales.

- Impulsar los procesos de generación distribuida: cogeneración, autoabastecimiento, pequeña producción y de diversas formas descentralizadas de producción de energía eléctrica.

- Reforzar la vinculación de los institutos de investigación con las empresas del sector energético y promover el uso racional de la energía.

Las modificaciones propuestas a la Ley de Petróleos Mexicanos estaban encaminadas a permitir que Pemex cuente con autonomía presupuestal, de gestión y de operación, así como a la integración de sus cuatro organismos subsidiarios en una sola empresa. Planteaba modificar la integración de su Consejo de Administración, reduciendo el número de sus integrantes a nueve, prescindiendo de la participación de los Secretarios de Estado distintos al de Energía y de los representantes del Sindicato de Trabajadores, e incrementando el número de Consejeros Profesionales y la incorporación del Director de la CFE. También proponía la Ratificación del Director General de Pemex por el Senado de la República. Además, el presupuesto de Pemex sería incorporado al PPEF sin que la SHCP pueda modificarlo y el superávit de operación sería aplicado en el siguiente año como ingreso del organismo y destinarse a la atención de sus prioridades.

Federal de las Entidades Paraestatales; Ley de la Comisión Nacional de Hidrocarburos; Ley de Servicio Público de Energía Eléctrica; Ley para el Aprovechamiento de Energías Renovables; Ley de la Comisión Reguladora de Energía; Ley de Instituciones de Crédito, y la expedición de una nueva ley para crear el Fondo para la Estabilidad de los Ingresos Petroleros. 
Las modificaciones a la Ley Reglamentaria del Artículo 27 Constitucional reiteraban la autonomía de gestión y presupuestaria de Pemex, buscando reducir la emisión de gases de efecto invernadero contribuyendo al desarrollo y uso de fuentes de energías alternativas. Se permitiría a Pemex disponer de recursos propios para su inversión aprobados previamente por el Congreso, y se establecía que su régimen impositivo debería permitirle operar y crecer productiva, financiera y tecnológicamente para garantizar la seguridad energética nacional. ${ }^{30}$

Se planteaba modificar, en la Ley federal de Derechos, la tasa del Derecho Ordinario Sobre Hidrocarburos de 71.5 a $62.5 \%$, en cinco años; así como el límite del monto de deducción de costos, gastos e inversiones deducibles por barril de petróleo de 6.50 a 8.00 USD; para el gas natural se aumenta el límite de 2.70 a 3.00 usD por cada mil pies cúbicos. Actualizar la tabla del Derecho Sobre Hidrocarburos para el Fondo de Estabilización al establecer como piso un precio del barril de petróleo de 80 USD. Incrementar el Derecho para la Investigación Científica y Tecnológica de 0.65 a $1.00 \%$ del valor anual del petróleo crudo y gas natural extraídos en el año.

En la Ley Orgánica de la Administración Pública Federal, se establecía que la SHCP deberá compensar la disminución de la proporción del ingreso petrolero con la recaudación de otras fuentes. Se constituye la obligación de la SENER para presentar al Congreso un informe cuatrimestral sobre el desempeño del Consejo de Administración de Pemex. Se eliminaba la facultad de la SENER de aprobar los principales proyectos de exploración y explotación de hidrocarburos que elabore Pemex. Se proponía la creación de un Instituto Nacional de Energías Renovables como organismo público descentralizado de la APF, con personalidad jurídica, patrimonio propio, autonomía técnica y de gestión, sectorizado en la SENER con el objetivo de coordinar y realizar investigación científica básica y aplicada, de las fuentes de energía renovables, la eficiencia y el ahorro de energía.

En cuanto a la Ley de la Comisión Nacional de Hidrocarburos, se propuso transformar a dicho organismo desconcentrado en descentralizado, con personalidad jurídica y patrimonio propios, con autonomía técnica, operativa, funcional y de gestión. Los Comisionados serán designados por el Ejecutivo Federal y ratificados por el Senado.

\footnotetext{
30 Se proponía que en la Ley Federal de Presupuesto y Responsabilidad Hacendaria se establezca que los ingresos petroleros excedentes no podrán utilizarse para sufragar erogaciones adicionales a las aprobadas en el PEF o para compensar la disminución en la recaudación de ingresos no petroleros. Tampoco podría ser compensada por el Fondo de Estabilización de los Ingresos Petroleros.
} 
Economía Informa núm. 385 marzo - abril • 2014 - "

En la Ley del Servicio Público de Energía Eléctrica se definía a la CFE como una empresa pública con fines productivos, dotada de autonomía presupuestal y de gestión. Se incorpora al objeto de la CFE, reducir emisiones de gases de efecto invernadero, el uso de fuentes de energía renovable, impulsar acciones de adaptación y mitigación de los efectos del cambio climático. ${ }^{31}$

Se pretendía además, transformar a la Comisión Reguladora de Energía de organismo desconcentrado a descentralizado, con personalidad jurídica y patrimonio propios, autonomía técnica, operativa, funcional y de gestión. Los Comisionados de la CRE serán ratificados por el Senado.

Se propuso la creación de la Ley del Fondo para la Estabilidad de los Ingresos Petroleros, con el objeto de acumular y capitalizar los ingresos obtenidos de los hidrocarburos. El Fondo se integraría por las aportaciones que realice Pemex cuando en el precio promedio ponderado del barril de petróleo crudo exportado exceda el fijado por el Congreso de la Unión en la Ley de Ingresos de la Federación, hasta 33\%. Los recursos del Fondo serían administrados en una cuenta del Banxico y sólo podrán ser utilizados por resolución expresa de la Cámara de Diputados, previa solicitud de la SHCP. Los recursos del fondo se utilizarían sólo para fines específicos: compensar diminuciones inesperadas de los ingresos petroleros; financiar proyectos prioritarios para el desarrollo de las entidades públicas del sector de hidrocarburos; financiar proyectos de infraestructura de transporte masivo de personas que contribuya al ahorro de combustibles y coadyuve a la transición energética y para proyectos de investigación y desarrollo que beneficien la salud de los mexicanos.

\section{V.4 La Reforma ${ }^{32}$}

La reforma aprobada por el Congreso de la Unión modificó tres artículos constitucionales (como lo propuso el PAN). En lo que se refiere a las reformas a

\footnotetext{
31 Se modifica la composición de la Junta de Gobierno de la CFE, integrada por nueve miembros, prescindiendo de la participación de otros Secretarios de Estado diferentes al de Energía y de los representantes del sindicato, y se incrementa el número de Consejeros Profesionales. El anteproyecto de ingresos y de presupuesto de egresos de la CFE no podrá ser modificado por la SHCP. El organismo deberá promover la cogeneración a gran escala, en las instalaciones de Pemex, para aumentar la eficiencia energética reducir las emisiones contaminantes. Se establecen nuevas disposiciones en materia de deuda para brindar mayor autonomía e independencia a la CFE respecto a la SHCP. El Ejecutivo Federal deberá proporcionar información sobre las transferencias económicas a la CFE para cubrir los subsidios. El monto deberá especificarse en el PEF correspondiente.

32 Se refiere al Decreto por el que se Reforman y Adicionan diversas disposiciones de la Constitución Política de los Estados Unidos Mexicanos en materia de Energía. Gaceta Parlamentaria, 11 de diciembre de 2013.
} 
los párrafos cuarto, sexto y octavo del Artículo 25; se establece que el Gobierno Federal mantendrá la propiedad y el control de las Empresas Productivas del Estado, y que tratándose de la planeación y el control del sistema eléctrico nacional y del servicio público de transmisión y distribución de energía eléctrica, así como de la exploración y extracción de petróleo y demás hidrocarburos, la Nación llevará a cabo dichas actividades en términos del artículo 27 de la propia Constitución. Se establece además que la Ley dictará normas en cuanto a la administración, organización, funcionamiento, procedimientos de contratación y demás actos jurídicos que celebren las empresas productivas del estado, así como el régimen de remuneraciones y las demás actividades que podrán realizar.

Entre las modificaciones al artículo 27 en materia de energía eléctrica, se establece que el Estado puede celebrar contratos con particulares y que las leyes determinarán la forma en que podrán participar en las actividades relacionadas con la industria eléctrica. En cuanto a petróleo e hidrocarburos, se establece que la propiedad de la nación es inalienable y no se otorgarán concesiones; sin embargo, también establece que el Estado puede realizar asignaciones o contratos para llevar a cabo las actividades de explotación y extracción del petróleo y demás hidrocarburos.

En cuanto a las modificaciones al artículo 28 constitucional en materia energética, se establece que no constituirán monopolios la planeación y el control del sistema eléctrico nacional, así como el servicio público de transmisión y distribución de energía eléctrica, y la exploración y extracción de petróleo y de los demás hidrocarburos. También establece que el Estado contará con un fideicomiso denominado Fondo Mexicano del Petróleo para la Estabilización y el Desarrollo y que el Ejecutivo contará con la Comisión $\mathrm{Na}-$ cional de Hidrocarburos y la Comisión Reguladora de Energía como órganos reguladores.

Hasta aquí, las modificaciones propuestas no parecen presentar cambios profundos en la forma en que venía operando el sector energético del país, es decir, se prohíben las concesiones pero se permite el establecimiento de contratos. No obstante, la reforma presenta modificaciones importantes al marco legal en 21 artículos transitorios. A continuación se describen las reformas más relevantes.

En el artículo tercero transitorio se establece:

- Un plazo de dos años para que Pemex y cFe se conviertan en empresas productivas del estado. 
Economía Informa núm. 385 marzo - abril • 2014 - "

- El Congreso tiene un plazo de 120 días para adecuar el marco jurídico para regular los contratos de servicios, de utilidad o producción compartida, o de licencia, para que los particulares lleven a cabo por cuenta de la Nación las actividades de exploración y extracción de petróleo y de los demás hidrocarburos. El Estado definiría el modelo contractual que maximice los ingresos de la Nación.

En este caso, la ambigüedad del artículo se encuentra en que si bien la propia Constitución prohíbe las concesiones, la introducción en este artículo de los contratos "de licencia" pareciera admitirlos aunque con un nombre distinto. Además, en el artículo cuarto transitorio, al establecer que el Congreso deberá regular las modalidades de pago a los particulares, establece que éstos serán: en efectivo, para los contratos de servicio; con un componente de la utilidad, para los contratos de utilidad compartida; con un porcentaje de la producción obtenida, para los contratos de producción compartida y con la transmisión onerosa de los hidrocarburos una vez que hayan sido extraídos del subsuelo, para los contratos de licencia. Cabe señalar que esta transmisión onerosa de la propiedad de los hidrocarburos en los contratos de licencia, no es más que la forma común en la que se paga a las concesiones, por lo que de esta forma, se da vuelta a la prohibición que sobre las mismas se encuentra contenida en el Artículo 25.

Entre otras cuestiones que llaman la atención se encuentra (en el décimo sexto transitorio) que el Ejecutivo contará con un año posterior a la aprobación de la Reforma para crear el Centro Nacional de Control de Gas Natural, que estará encargado de la operación del sistema nacional de ductos de transporte y almacenamiento y al cual Pemex transferirá los recursos y contratos necesarios para que cumpla con sus funciones.

Se creará también, en el mismo plazo de un año, el Centro Nacional de Control de Energía, como organismo público descentralizado encargado del control operativo del sistema eléctrico nacional, de operar el mercado mayorista, del acceso a la red; para lo cual cFE transferirá los recursos que el Centro requiera.

\section{Consideraciones finales}

Pemex además de ser un símbolo de soberanía se ha constituido como un pilar de las finanzas públicas del país. No obstante, se trata de una empresa cuya situación financiera se ha deteriorado en los últimos años como producto de la pesada carga fiscal de la que ha sido objeto. En comparación con las petroleras 
de capital estatal mayoritario en América Latina (Petrobras y PDVSA), así como respecto de otras compañías del sector a nivel internacional, Pemex es la que enfrenta mayores impuestos; situación que incide directamente en sus pérdidas netas al final de cada ejercicio fiscal. Sin embargo, es preciso indicar que el margen neto de Pemex (esto es, las utilidades antes de impuestos respecto de sus ingresos) resultó ser el más alto de entre las petroleras analizadas. Lo anterior implica que los principales obstáculos que enfrenta la paraestatal mexicana se encuentran en su estructura organizacional y en su régimen fiscal. Por otro lado, no se encontró un sustento claro para apoyar la participación del sector privado en el sector petrolero nacional, pues Pemex cuenta con ingresos y la rentabilidad suficientes para hacer frente a sus programas de inversiones. Lo que se requería con urgencia era una reforma fiscal que liberara a la paraestatal se su pesada carga tributaria.

Las iniciativas presentadas por las tres principales fuerzas políticas representadas en el Congreso diferían en la forma en que pretenden atender la problemática del sector. Por un lado, dos de las iniciativas (la del Ejecutivo Federal y la del PAN) proponían reformar la Constitución para dar cabida a la iniciativa privada (nacional y extranjera) a lo largo de la cadena productiva tanto del petróleo como de la electricidad; sin embargo, diferían en la manera en que dicha participación se llevaría a cabo. En la propuesta del Ejecutivo, el sector privado participaría a través de contratos; mientras que en la propuesta del PAN lo haría bajo la figura de concesiones. Al final, el congreso aprobó un término ambiguo "licencias", que parece ajustarse más al de concesión. Por su parte, la propuesta del PRD se centraba en modificaciones a ordenamientos distintos a la Constitución, pero que de igual forma intentaba modernizar y dar mayor transparencia a la operación del sector.

Otros puntos de coincidencia entre las tres iniciativas se referían a la necesidad de reducir la carga impositiva que pesa sobre Pemex; a la constitución de fondos petroleros (PRD y PAN), dotar a Pemex de autonomía de gestión (PAN y PRD), así como a ubicar a las empresas estatales del sector fuera del presupuesto público (PAN y PRD). La necesidad de incluir el cuidado al medio ambiente y la reducción de gases de efecto invernadero se encuentra, de cierta forma, incluida en las tres iniciativas. Un elemento adicional de coincidencia entre las tres principales fuerzas políticas, era mantener al Estados como rector de la política energética del país.

La reforma al sector energético permitirá la plena participación del sector privado nacional y extranjero en actividades de extracción y exploración de petróleo, así como en la generación de electricidad. Si bien el sector privado 
Economía Informa núm. 385 marzo - abril • 2014 - "

ya participaba en dichas actividades, anteriormente lo hacía bajo la figura de contratos; lo que hizo la reforma fue ampliar la gama de contratos y licencias, así como aumentar las opciones de pago que las empresas pueden recibir como contraprestación por sus servicios.

De mantenerse vigentes estos ordenamientos y de profundizarlos mediante la aprobación de regulaciones secundarias, en los próximos años será posible observar el desmantelamiento gradual tanto de Pemex como de CFE, ya que la propia reforma establece que deben transferir sus redes de distribución a los nuevos entes reguladores del mercado.

A fin de que el sector energético contribuya a la industrialización y desarrollo económico del país, bajo las nuevas leyes aprobadas, es necesario que se promueva la creación de cadenas productivas y de abastecimiento, que permitan a las pequeñas y medianas empresas mexicanas articularse con los nuevos participantes del sector. De lo contrario, la apertura del sector energético se sumará a los resultados poco satisfactorios que se han observado en sectores que anteriormente eran controlados por empresas estatales, que fueron abiertos a la participación del sector privado y que actualmente se han convertido en mercados con escasa competencia, tales como las telecomunicaciones, los ferrocarriles y la banca comercial.

\section{Bibliografía}

Aguilar Camín H., y Lorenzo Meyer (1991), A la Sombra de la Revolución Mexicana. Cal y Arena.

Campodónico, H. (2007), La Gestión de la Industria de Hidrocarburos con Predominio de Empresas del Estado, CEPAL, Santiago de Chile.

CePAl (2013), Panorama Fiscal de América Latina y el Caribe. Reformas Tributarias

y Renovación del Pacto Fiscal. Santiago de Chile.

Centro de Estudios de las Finanzas Públicas, Cámara de Diputados (2008), Puntos Relevantes de la Reforma Energética.

Centro de Estudios de las Finanzas Públicas, Cámara de Diputados (2009), Principales cambios al Régimen Fiscal de Pemex.

Gaceta del Senado, 31 de julio 2013. Iniciativa con Proyecto de Decreto que Reforma, Adiciona y Deroga Diversas Disposiciones a Los Artículos 25, 27 Y 28 de la Constitución Política de los Estados Unidos Mexicanos. http://www.senado.gob.mx/sgsp/gaceta/62/1/2013-07-31-1/assets/documentos/Inic_PAN_ art.25-27-y-28-Const.pdf 
Gaceta del Senado, 17 de agosto 2013, Iniciativa de Decreto por el que se Reforman los artículos 27 y 28 de la Constitución Política de los Estados Unidos Mexicanos.http://www.senado.gob.mx/sgsp/gaceta/62/1/2013-08-14-1/assets/documentos/INICIATIVA_PRESIDENTE_ARTS_27_Y_28_CONSTITUCIO_ NALES.pdf.

Gaceta del Senado, 20 de agosto 2013, Iniciativa con proyecto de decreto por el que se reforman, derogan y adicionan diversos ordenamientos en materia de reforma integral del sector energético nacional. http://www.senado.gob.mx/ sgsp/gaceta/62/1/2013-08-20-1/assets/documentos/INI_PRD_SECTOR_ ENERGETICO.pdf.

García, B. (1993), Modernización del Estado y Empresa Pública. InAP.

García, B., (2000), Situación Actual y Perspectivas de Pemex, unam

Huerta, C., y Ruiz,. F. (2012), "Petrobras: Petróleo, Finanzas Públicas y Desarrollo", en Análisis, núm. 12, mayo-agosto de 2012.

Ley Reglamentaria del Artículo 27 Constitucional en el ramo de petróleo. http:// www.diputados.gob.mx/LeyesBiblio/pdf/206.pdf

Manzano, V. (2013), Análisis del Desempeño Operativo, Fiscal y Financiero de Pemex 2002-2012. UNAM.

Pemex. Informe de Labores, varios años.

Pemex (2012), Estados Financieros Consolidados.

PDVSA (2012), Informe de Gestión Anual.

Rendón, R., Huehara, Y. y Corral, D., (2013), “Pemex: ¿Falta de Competitividad o excesiva carga tributaria?”, en Energía a Debate, abril de 2013. 